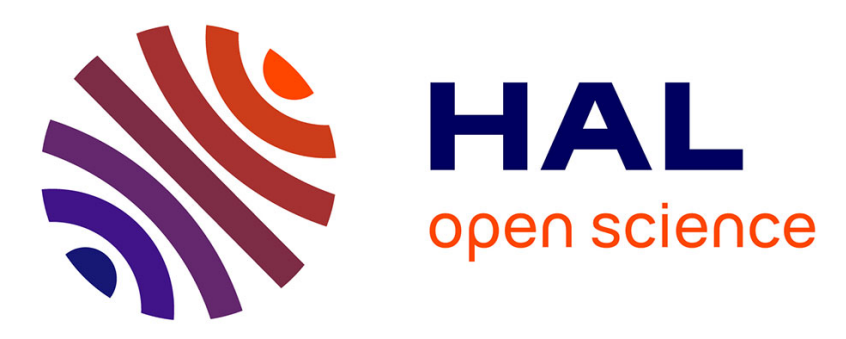

\title{
Conserved rules in embryonic development of cortical interneurons
}

\author{
Christine Laclef, Christine Métin
}

\section{To cite this version:}

Christine Laclef, Christine Métin. Conserved rules in embryonic development of cortical interneurons. Seminars in Cell and Developmental Biology, 2017, 10.1016/j.semcdb.2017.09.017 . hal-01618849

\section{HAL Id: hal-01618849 \\ https://hal.sorbonne-universite.fr/hal-01618849}

Submitted on 18 Oct 2017

HAL is a multi-disciplinary open access archive for the deposit and dissemination of scientific research documents, whether they are published or not. The documents may come from teaching and research institutions in France or abroad, or from public or private research centers.
L'archive ouverte pluridisciplinaire $\mathbf{H A L}$, est destinée au dépôt et à la diffusion de documents scientifiques de niveau recherche, publiés ou non, émanant des établissements d'enseignement et de recherche français ou étrangers, des laboratoires publics ou privés. 


\section{Accepted Manuscript}

Title: Conserved rules in embryonic development of cortical interneurons

Authors: Christine Laclef, Christine Métin

PII: $\quad$ S1084-9521(17)30241-0

DOI: $\quad$ http://dx.doi.org/10.1016/j.semcdb.2017.09.017

Reference: $\quad$ YSCDB 2383

To appear in: $\quad$ Seminars in Cell \& Developmental Biology

Received date: $\quad 1-6-2017$

Revised date: $\quad$ 8-9-2017

Accepted date: $\quad 11-9-2017$

Please cite this article as: Laclef Christine, Métin Christine.Conserved rules in embryonic development of cortical interneurons.Seminars in Cell and Developmental Biology http://dx.doi.org/10.1016/j.semcdb.2017.09.017

This is a PDF file of an unedited manuscript that has been accepted for publication. As a service to our customers we are providing this early version of the manuscript. The manuscript will undergo copyediting, typesetting, and review of the resulting proof before it is published in its final form. Please note that during the production process errors may be discovered which could affect the content, and all legal disclaimers that apply to the journal pertain. 


\title{
Conserved rules in embryonic development of cortical interneurons
}

By

\section{Christine Laclef ${ }^{1,2,3}$ and Christine Métin ${ }^{1,2,3}$}

1, INSERM, UMR-S839, Paris, France,

2, Sorbonne Universités, UPMC University Paris 6, UMR-S839, Paris, France,

3, Institut du Fer à Moulin, Paris, France

\section{Correspondence:}

Christine Métin

INSERM UMR-S839, Institut du Fer à Moulin,

17, rue du Fer à Moulin

75005 Paris

email : christine.metin@inserm.fr

\begin{abstract}
This review will focus on early aspects of cortical interneurons (cIN) development from specification to migration and final positioning in the human cerebral cortex. These mechanisms have been largely studied in the mouse model, which provides unique possibilities of genetic analysis, essential to dissect the molecular and cellular events involved in cortical development. An important goal here is to discuss the conservation and the potential divergence of these mechanisms, with a particular interest for the situation in the human embryo. We will thus cover recent works, but also revisit older studies in the light of recent data to better understand the developmental mechanisms underlying cIN differentiation in human. Because cIN are implicated in severe developmental disorders, understanding the molecular and cellular mechanisms controlling their differentiation might clarify some causes and potential therapeutic approaches to these important clinical conditions.
\end{abstract}

\section{Main Abbreviations:}

$\mathrm{CB}$, calbindin 
cIN, cortical interneurons

CGE, caudal ganglionic eminence

$\mathrm{CP}$, cortical plate

$\mathrm{CR}$, calretinin

GABA, gamma-aminobutyric acid

GFP, green fluorescent protein

iSVZ, inner subventricular zone

IZ, intermediate zone

LGE, lateral ganglionic eminence

MGE, medial ganglionic eminence

MZ, marginal zone

nNOS, neuronal nitric oxide synthase

NPY, Neuropeptide Y

oSVZ, outer subventricular zone

POA, pre optic area

$\mathrm{PV}$, parvalbumin

SP, subplate

SST, somatostatin

SVZ, subventricular zone

VIP, vasoactive intestinal peptide

VZ, ventricular zone

Keywords: human cortex, cortical interneurons, GABA, medial ganglionic eminence, caudal ganglionic eminence,

\section{Introduction}

The unique cognitive abilities of the human brain most likely result from a relative expansion of regions responsible for associative and executive function in the cerebral cortex. During the course of evolution, the neocortex underwent a major expansion in its relative size and a dramatic complexification. Nevertheless, many aspects of the cortical organization and especially the underlying developmental processes, display a number of common and evolutionary conserved features in mammals. In all vertebrates the rostral-most part of the embryonic brain, called the telencephalon, is rapidly subdivided in two main regions, the dorsal pallium and ventral subpallium.

Cortical neurons can be subdivided in two major classes: the excitatory glutamatergic pyramidal projection neurons, and the inhibitory GABAergic interneurons. These two functional classes arise from spatially and molecularly segregated progenitors located respectively in the pallium and the subpallium. Importantly, the proper functions of the mature cerebral cortex require a balanced and coordinated action of these two major neuronal subtypes.

The embryonic development of the cerebral cortex relies on a highly precise orchestration of patterning events along multiple axes, and on a tight coordination of 
cell proliferation, commitment, migration and differentiation. The incorrect formation of cortical organization and circuitry certainly leads to cognitive impairments and to psychiatric or neurological disorders. In particular, disturbing cortical inhibition results in severe clinical conditions, ranging from epilepsy to schizophrenia and autism disorders. This strongly suggests that the expansion of the cortex in mammals were rendered possible only by the co-evolution and expansion of inhibitory interneurons as well as excitatory neurons.

\section{Diversity of the mature cIN}

Locally projecting GABAergic interneurons, identified by Ramon y Cajal in 1899 as «short axon cells », represent a small percentage of the total neurons in the neocortex, $\sim 20-30 \%$, with the percentage varying substantially between cortical layers, areas and species (the remaining $~ 80-70 \%$ consisting in glutamatergic excitatory pyramidal neurons). In humans the percentage of cortical interneurons (cIN) is higher than in the mouse and can even reach $40-45 \%$ in the superficial cortical layers [1-3]. Ramon y Cajal already noticed a century ago that interneurons are more abundant and morphologically diverse in the primate neocortex (and particularly, in the human neocortex).

GABAergic cIN are inhibitory in the adult cortex and have a number of common features, including aspiny dendrites and local projections within the same cortical column or to adjacent columns in the cortex [4]. However they consist in a very heterogeneous population of neurons. The diverse subtypes are classified according to their location, morphology, target specificity, as well as electrophysiological and molecular characteristics. A number of excellent reviews highlight the trends in classification and nomenclature of GABAergic cIN [5-10]. The molecular criteria include different neurotransmitters and their synthesizing enzymes, neurotransmitter receptors, neuropeptides, calcium-binding proteins, transcription factors, structural proteins, connexins, ion channels and membrane transporters. The functional markers used to classify cIN are mainly the parvalbumin (PV), calbindin (CB), calretinin (CR), somatostatin (SST), vasoactive intestinal peptide (VIP), neuropeptide Y (NPY), reelin, neuronal nitric oxide synthase (nNOS).... Altogether, it has been suggest that the neocortex contains over 20 molecularly distinct classes of interneurons, and recent analyses of single cell transcriptomics further emphasized the cIN diversity [11-13]. The human and rodent cortices comprise equivalent classes of cIN although some morphological types seem specific to the human cortex [2]. cIN in rodents are presently reassembled into three main non-overlapping classes, each class expressing exclusively one out of the three following markers, PV, SST or the receptor to 5HT3a (5HT3aR) [9,14,15]. PV-expressing (PV(+)) cIN account for $40 \%$ and SSTexpressing (SST(+)) cIN for $30 \%$ of the total number of GABAergic interneurons in the adult mouse cortex [15-17]. Similarly, PV and SST label two non-overlapping populations of GABAergic cIN in the adult human parietal cortex and in the somatosensory cortex of the young monkey [18]. But these two populations account for only 20\% (PV(+)) and 25\% (SST(+)) of the total number of interneurons in primates [18]. In primates, the relative decrease in PV and SST cIN is correlated with a strong increase in cIN expressing CR.

The attainment of subtype characteristics is progressively achieved during ontogenesis, after weeks of post-natal maturation. Dynamic changes in the expression of markers as well as specific schedules of development among species have hindered 
the establishment of a complete and continuous overview of cIN development. The expression of PV is delayed during development, starting after birth in the mouse cortex, and by mid-term in the human cortex, together with SST and NPY. Certain calcium-binding proteins moreover change their cellular specificity during development. In the human embryo, CR antibodies label cortical plate neurons that resemble pyramidal neurons in addition to GABAergic neurons, and $\mathrm{CB}$ antibodies progressively label cortical pyramidal cells in addition to GABAergic cIN during cortical maturation [19-22].

During the last decades, fate-mapping approaches and genetics analyses in the mouse have demonstrated that the diversity of the functional markers expressed by the mature cIN largely depends on the ontogenic markers expressed by these cells at earlier stages $[7,9,15]$. Ontogenic markers are related to the spatial origin of the progenitors and to their date of birth. Maturing neurons can either express a temporal sequence of ontogenic markers ( $N k x 2.1$ and then $L h x 6$ that is activated by $N k x 2.1$ ), or maintain forever the expression of an early marker that signs their ontogenic origin (Coup-TFII).

In contrast to the monkey cortex that presents very similar -although drastically shortened- sequence of prenatal development as compared to the human cortex, some embryonic structures that develop in the human cortex have no equivalent in the mouse cortex (Fig.1). However, two recent studies that analyzed in the human cortex and basal telencephalon, the distribution of ontogenic markers discovered in the mouse brain, have changed our understanding of cIN neurogenesis in humans $[18,23,24]$.

\section{Origin, commitment and molecular determinants of cIN}

A number of experimental approaches, such as tracing studies, in utero transplantation experiments, in vitro migration and differentiation assays, or gene knock-out in mice, have demonstrated the subpallial origin of cIN in rodents and the preponderant role of the medial ganglionic eminence (MGE) in producing cIN [2530], review in [31-34].

\subsection{The MGE and CGE are the main sources of cIN in rodents: spatial and temporal origin}

The embryonic subpallium of mammals is subdivided into five major proliferative regions: three ganglionic eminences (GEs) initially defined by their location, medial (MGE), lateral (LGE) and caudal (CGE), the preoptic area (POA) and the septum anlage. All these anatomical subdivisions give rise to multiple neuronal types that differentiate locally or disperse tangentially before their terminal differentiation. The MGE gives rise to local projection neurons for the globus pallidus, the amygdala and the septum, and to migrating interneurons destined to the cortex, striatum or hippocampus, and also produces migrating and resident oligodendrocytes [35,36]. The LGE produces the local striatal projection neurons and interneurons migrating to the olfactory bulb. The CGE is considered as a caudal extension of the MGE ventrally, and a caudal extension of the LGE, dorsally. The CGE generates the local caudal striatal and pallidal neurons, as well as different subtypes of migrating interneurons destined for the cortex (caudal regions), hippocampus, amygdala and other limbic system nuclei [37]. 
Lineage tracing analyses in the mouse have revealed that cIN are produced in the MGE and the CGE and, to a lesser extent in the POA [27,30,38,39](Fig.2a). The MGE generates from E10.5 to E14.5 the large majority of all cIN (50\%-70\%), in particular the PV and SST populations (Fig.2B, 2C). The different subtypes of MGEderived cIN are generated at different time point in a precise temporal sequence [36,40-43]. The CGE is the second region in the basal forebrain that contributes another large contingent of cIN (30\%-40\% of all cIN) identified by the expression of the $5 \mathrm{HT} 3 \mathrm{a}$ receptor $(5 \mathrm{HT} 3 \mathrm{aR})$ and additional markers such as CR, VIP or reelin. The CGE is responsible for producing the late-born cIN $[16,40,42,44]$. These neurons preferentially $(75 \%)$ integrate the upper cortical layers independently of their birthdate (Fig.2A, 2B). A third region, the POA produces a small fraction of cIN, about $5 \%-10 \%$ of highly diverse subtypes with a large geographical distribution (Fig. 2B, 2E) $[39,45]$.

\subsection{Genetic control of the subpallium development}

Here, we present a summary of the molecular mechanism that pattern the GEs and specify the fate of cIN generated in the mouse GE subdivisions (Fig.2B) and describe the expression pattern of same genes in the human telencephalon (Fig.3A, B).

Several families of transcription factors control the development of the subpallium and specify the fate of neurons originating in its neuroanatomical subdivisions. Some developmental genes are common determinants whereas others generate regional diversity.

\subsection{1. cIN determinants with a widespread expression in the subpallium}

Genes widely expressed within the three ganglionic eminences, especially the transcription factors Ascll or Dlx, control the embryonic development of the subpallium and the generation and/or differentiation of GABAergic cells, including cIN. Mice lacking Ascll or Dlxl\&2 in the GE lack $50 \%$ to $80 \%$ of cortical GABAergic neurons, confirming the origin of cortical GABAergic neurons in the ventral telencephalon [46-48] and demonstrating the existence of parallel and overlapping mechanisms of GE patterning [49,50].

Ascl1 (also known as Mash1) is a proneural transcription factor strongly expressed in the subpallial ventricular zone (VZ) and subventricular zone (SVZ) (Fig.2B) required for the neurogenesis of GABAergic neurons [47,48,51,52] and for the generation of oligodendrocytes by restricting the number of $D l x$-expressing progenitors [53,54]. In the mouse, Ascll is expressed at very low level in pallial progenitors $[47,55]$. In primates, ASCL1 shows a clear frontier of expression at the pallium/subpallium boundary, because ASCL1-expressing $(A S C L 1(+))$ cells are numerous in the GE and sparse in the pallial VZ and SVZ (Fig.3B, Fig.4). According to Hansen et al. [23] and Ma et al. [18], ASCL1(+) cells located in the pallium coexpress pallial markers, PAX6 or TBR2, but neither GAD65/67 nor GABA, suggesting that they very unlikely contribute to the GABAergic lineage. Because Ascll is maintained in a proportion of cIN that reach the cortex [16], the pallial or subpallial origin of Ascl1(+) cells that later differentiate as GABAergic interneurons remains controversial and needs to be clarified.

Dlx homeobox genes (Dlxl\&2, Dlx5\&6) show a widespread expression throughout the subpallium [56,57] and are required for the differentiation of the three 
GEs. They are also involved in the craniofacial development. In the subpallium, Dlxl \&2 expression commences as progenitors transit from the VZ to the SVZ and is extinguished as cells differentiate after their phase of migration (Fig.2B) [58,59]. In the human brain, $D L X 2$ is strongly expressed in GE progenitors and more faintly in cells located in the cortex (Fig.3B, Fig.4A-C) [23,60]. The capacity of $D L X 2$ cells to proliferate in the human cortex is debated $[23,61]$. Dlx $1 \& 2$ promote the expression of glutamic acid decarboxylase (Gad67, also known as Gad1) and vesicular GABA transporter (VGAT) [62,63]. Dlx genes are thus essential for both the differentiation of GABAergic interneurons and the tangential migration of their precursors. Dlxl and Dlx2 are functionally redundant and a $80 \%$ reduction in GABAergic cIN is uniquely observed in mice with Dlxl\&2 ablation [25,29,46,64]. Dlx2 activates Dlx5 gene expression [58]. Accordingly, Dlx5\&6 are expressed in more mature cells than Dlxl\&2 [65].

\subsection{2. cIN determinants with a restricted expression in the subpallium}

\subsubsection{Restricted to the $M G E$}

Nkx2.1 (Titf1/Ttf1) is a homeobox gene expressed early in the VZ and SVZ of the MGE and the POA, which controls the formation of the MGE and regulates the neurogenesis and differentiation of two main populations of MGE-derived GABAergic interneurons, the PV(+) and SST(+) cIN (Fig.2B) [27,40,41,66,67]. $N k x 2.1$ expression is induced by sonic Hedgehog ( $\mathrm{SHH})$ in the ventral forebrain [68]. SHH expression and signaling level differ in the dorsal and ventro-medial parts of the MGE. PV(+) and SST(+) cIN seem specified by different levels of SHH. They are produced in different MGE regions, with SST(+) interneurons induced by higher level of SHH signaling in the dorsal MGE [17,69-71], Review in [72].

In the mouse, the genetic ablation of $N k x 2.1$ results in $50 \%$ loss of GABAergic cIN, principally early migrating $D l \times 2$-expressing $(D l \times 2(+))$ cells, but spares $D l \times 2(+)$ cells that originate in the CGE. $N k x 2.1$ seems to regulate the switch in the class of neurons generated at different time point and fated to different targets. For example, $N k x 2.1$ is downregulated in GABAergic post-mitotic cells that migrate to the cortex, but maintained in GABAergic interneurons migrating to the striatum $[73,74]$.

In humans, the localization and extension of the MGE has been identified recently in a KI67(+) rostro-medial domain of the GE thanks to the strong expression of NKX2.1 (Fig.3B) $[3,18,75]$. The persistence of $N K X 2.1$ expression in cIN migrating through the cortex is debated. Two groups reported scattered NKX2.1-expressing $(N K X 2.1(+))$ cells at GW24 and suggested that NKX2.1 is down regulated in MGE cells after they reach the cortex, as in mice [18,23]. A third group [60] described $N K X 2.1(+)$ cells among cortical progenitors, and found a high percentage of KI67(+) and PAX6(+) cells $(80 \%)$ in the $N K X 2.1(+)$ population (labeled " $€$ " in Fig.4C,D). These authors reported nevertheless a low percentage of $N K X 2.1(+)$ cortical progenitors (3-5\% of VZ cells and 5-9\% of SVZ cells at GW15-GW22). NKX2/1(+) cells thereafter distributed in the intermediate zone (IZ) and subplate (SP). On the second half of the gestation, they distributed in all cortical layers and co-expressed PV or SST (Fig.4C,D) [76].

Lhx6 is a transcription factor of the LIM homeodomain family directly activated by $N k x 2.1$ and essential for the tangential migration of cIN precursors and for their differentiation in the cortex [27,77-79]. Lhx6 is expressed in post-mitotic cIN lacking progenitor markers and is maintained in both $\mathrm{PV}(+)$ and SST(+) MGE-derived cIN 
(Fig.2B) [27,42,57,78-81]. LHX6 is also expressed in human MGE-derived cIN (Fig.3B) [23]. Lhx6 is sufficient to rescue the production of cIN from Nkx2.1-/subpallial cells, suggesting that the major function of $N k x 2.1$ is to initiate the transcription of Lhx6 in cIN progenitors [64]. Lhx6 functions in part through promoting Arx and $\mathrm{Cxcr} 7$ expression [82].

Sox6 functions downstream $L h x 6$ and is expressed in MGE-derived cIN from postmitotic stage to adulthood. Sox6 is required for normal PV(+) and SST(+) interneurons development, final positioning and maturation into the cortical layers (Fig.2B) [7,83]. In the developing mouse forebrain, Sox6 is strongly expressed in MGE-derived cIN and, at lower level, in pallial VZ where it cooperates with Ngn2 to repress Ascll and maintain pallial identity and pallial/subpallial patterning [83]. The MGE in human strongly expresses SOX6. $80 \%$ of PV(+) cells and $90 \%$ of SST(+) cells co-express SOX6 in the adult cortex, suggesting that they originate in the MGE (Fig.3B) [18]. A population of SOX6(+) pallial progenitors co-expresses PAX6 but not GABA, and likely represents progenitors of cortical glutamatergic projection neurons (Fig.3A, Fig.4C).

\subsubsection{2.restricted to the $C G E$}

CGE-derived cIN migrate later than MGE-derived cIN, do not require $N k x 2.1$ function and differentiate as $\mathrm{CR}(+)$ and $\operatorname{VIP}(+)$ neurons $[40,59,66]$. The molecular signals involved in their fate determination are much less characterized but involve Gsx2, CoupTFII, and Proxl [17,84-86]. Gene expression profiles in CGE and LGE are largely overlapping, suggesting that the CGE is a caudal expansion of the LGE (Fig.2D) [56,57,87]. In the mouse, cIN generated outside of the $N k x 2.1$-expressing proliferative domains derive from CGE progenitors and can be traced through their expression of Proxl in post-mitotic cells $[86,88]$. Proxl has a crucial role in the acquisition of CGE-derived cIN properties and is maintained in the mature cortex (Fig.2B) [86].

All CGE-derived cIN express the serotoninergic ionotropic receptor 5HT3aR [89]. $5 \mathrm{HT} 3 \mathrm{aR}$ is expressed in migrating and mature CGE- and POA-derived cIN that express neither PV nor SST, e.g. bipolar CR(+) (CALB2), VIP(+), CCK(+), reelin(+), and the multipolar NPY $(+)$ cIN [14,89-92]. This receptor is presently used to define in the mouse a cell population that represents about $30 \%$ of cIN, targets the superficial cortical layers and comprises a variety of functional subpopulations (Fig.2B) [14,17]. Because of the lack of antibodies against 5HT3aR, these interneurons have been characterized in transgenic mouse lines (Lee et al, 2010, [91] and the receptor cannot be used to identify the non-PV and non-SST GABAergic interneurons in human and non-human primates.

Coup-TFII $(N r 2 f 2)$ is an orphan nuclear receptor enriched in the CGE and required for the tangential migration of CGE-derived cIN in the mouse [84,93]. A small subset of Coup-TFII-expressing (Coup-TFII(+)) interneurons derives from the dorsal/caudal part of the MGE and co-expresses Sox6 [83]. Therefore, Coup-TFII shows a minimum overlap with Sox6 (Fig.2B).

In the human subpallium, COUP-TFII is expressed in a rostral-to-caudal increasing gradient (from LGE to CGE) identifying the CGE as a strongly labeled structure, with a high density of positive cells in the ventral part of the CGE (vCGE, Fig.3B) [75]. VZ and SVZ progenitors of the vCGE co-express KI67. COUP-TFII(+) 
cells in the dorsal CGE and LGE (dCGE, dLGE, Fig.3B) are post-mitotic and coexpress SP8 (see below). They could derive from the CGE and migrate toward the cortex $[18,23]$. COUP-TFII shows an abrupt decrease in expression at the palliumsubpallium boundary, but remains expressed at low level in the cortex [75]. The population of COUP-TFII(+) cortical cells is radially-oriented and co-expresses KI67 and PAX6 (Fig.4C,4D) [75]. This population very likely generates glutamatergic pyramidal neurons destined to cortical layers V and VI, which express COUP-TFII at low level [94].

Despite the small population of COUP-TFII(+) cells born in the MGE, COUP-TFII defines a third population of cIN that does not overlap with the PV(+) and SST(+) populations in the human and monkey cortex [18]. COUP-TFII is expressed in cIN that largely co-express the calcium-binding protein CR (80\% of COUP-TFII(+) interneurons[94]), showing that CR, together with reelin, are two fairly good markers of the same population [18]. In the adult human cortex, interneurons expressing COUP-TFII are distributed in the supragranular layers and exhibit specific physiological properties [94].

Sp8 (buttonhead-like zinc finger transcription factor) labels cIN derived from the dCGE (Fig.2B) and possibly from the dLGE [95]. $S p 8$ is also strongly expressed in the dLGE, where it is required for neurogenesis, migration and survival of olfactory bulb GABAergic interneurons [96]. Gsx2, a downstream target of SHH, controls the differentiation of interneurons upstream $S p 8$ [96-99]. In addition to regulating striatum development, Gsx2 is particularly enriched in the LGE/CGE and contributes to the specification of NPY(+), bipolar $\mathrm{CR}(+)$ and VIP(+) CGE-derived cIN [42]. $S p 8$-expressing $(S p 8(+))$ cIN are born at later embryonic stages (peak at E15.5) than MGE-derived cIN. $S p 8$ is moreover expressed at low level in the pallium where it controls the specification of cortical projection neurons $[96,100]$.

In humans, SP8 is strongly expressed in the SVZ of the dLGE and dCGE (Fig. 3B). $S P 8$ is weakly expressed in the cortical VZ and SVZ (Fig.4C,D). Because Gs $x 2$ is not expressed in the human cortex, SP8(+) cortical progenitors unlikely generate interneurons. They moreover express PAX6 and likely generate excitatory projection neurons. At adult stage, in human and monkey, the vast majority of $\mathrm{CR}(+), \mathrm{VIP}(+)$ and reelin(+) cIN express COUP-TFII and/or SP8, strongly suggesting that they are derived from the dLGE and CGE. These interneurons preferentially occupy the superficial cortical layers [101]. Altogether, SOX6(+), SP8(+) and COUP-TFII(+) cells account for nearly $90 \%$ of cIN [95].

\subsubsection{3. restricted to the $P O A$}

The POA is ventral and immediately adjacent to the MGE. Progenitor cells in both regions express $N k x 2.1$. Cells in the POA moreover express specific markers (Dbx1 and $S h h$ in the VZ, Nkx5.1 and Nkx6-2 in the SVZ), which are not expressed in the MGE. Reciprocally, Olig2, which is highly expressed in the MGE, is virtually absent from the POA $[57,67,102]$. In mice, the POA contributes a minor but highly diverse pool of cIN expressing PV (50\% of them in the somatosensory cortex), SST (25\%) or reelin $(15 \%)$, and for a very small number, CR, NOS or VIP $(2-4 \%)[39,67]$.

POA derived cells first migrate in a rostro-medial direction through the septal region to invade the cortex at intermediate or rostral telencephalic level. Migratory routes are mostly through the marginal zone (MZ) and the subplate (SP) [67]. 
Finally, the possibility that a small fraction of the LGE (dLGE) produce some cIN is not entirely ruled out, neither in rodents, nor in humans [25,26,28-30,88,103-107].

\section{The question of the pallial origin of cIN}

The relative increase in $\mathrm{CR}(+)$ interneurons observed in the human cortex as compared with the rodent cortex (illustrated in Fig.3A, to compare with the upper panel in Fig.2B), was initially attributed to a local production of GABAergic interneurons within the cortex and considered as a specific feature of the primate cortex $[61,76,108]$. This initial assertion was further supported by human cases with severe holoprosencephaly lacking substantial parts of the GE and showing the persistence of $\mathrm{CR}(+)$ neurons in the cerebral cortex [110].

The capacity of cortical progenitors in the human cortex to generate GABAergic interneurons is presently a controversial issue. This proposal was initially supported by two observations: 1) GABAergic neurons in the human cortex co-express ASCL1, and 2) pallial progenitors in humans do express $A S C L 1$ and/or $D L X 2$, two genes in the GABAergic lineage. As a consequence, it was proposed that ASCLI(+) pallial progenitors produce GABAergic neurons. We report below some arguments against.

Several studies in human showed that a large proportion of GABAergic cells (either GABA(+) or GAD65(+)) co-express ASCL1 in the human pallial SVZ, subplate (SP) and cortical plate (CP) (horizontal arrows in Fig.4A,B) [61,109,111]. By this time, Ascll and GABA (or GAD) co-expression had not been reported in the mouse cortex because cIN generated in the mouse subpallium down regulate Ascll after reaching the cortex (but not Dlx2) $[47,48,58,59]$ The co-expression of GABA and ASCL1 seemed thus unique to the human brain, and it was proposed that GABAergic neurons co-expressing ASCL1 represent a pool of interneurons produced in the pallium by $A S C L 1(+)$ pallial progenitors. A later study performed in mice revealed however, that CGE-derived cIN maintain the expression of Ascll as they migrate to the cortex as post-mitotic cells expressing Tuj1 or Map2 [16]. This study suggests that GABAergic neurons produced in the human subpallium can continue to express $A S C L$ after reaching the cortex and that $A S C L 1(+)$ GABA neurons present in the pallium can originate in the subpallium. As a consequence, two distinct cell lineages in the human telencephalon would express ASCL1: i) the cortical progenitors of excitatory neurons and ii) the CGE-derived precursors of cIN.

The pioneer study of Letinic et al. [61] reported the expression of ASCL1 and $D L X 2$ in dividing cells in the human cortex at GW14-24. Pallial progenitors in the human cortex were identified by their location in the cortical VZ/SVZ and by markers of proliferation (KI67 or BrdU incorporation). Studies in the mouse showed accordingly that transcription factors regulating cIN neurogenesis are expressed in areas that largely overpass the ventral subpallium and often includes the dorsal pallium (Cf. \$2.2.1 and §2.2.2.2 above). This is the case for ASCL1 and also SP8, COUP-TFII, or SOX6 (Fig.4C,D). Because these genes function in different genetic networks in their different areas of expression, they can both control the differentiation of GABAergic cells or oligodendrocytes in the subpallium and contribute to the differentiation of excitatory cortical cells in the pallium $[83,96,100]$. Therefore, the ASCL1(+) progenitors observed during the second trimester of gestation in the human cortex and from E64 to E88 in the monkey cortex 
$[61,108,109]$ cannot be attributed to the GABAergic lineage uniquely on the base of their expression of $A S C L 1$.

A remaining question is whether transcription factors such as $D L X 2$ and $N K X 2.1$ that control the differentiation of cIN in the subpallium, can orient the fate of dorsal progenitors toward a novel dorsal GABAergic lineage in the human forebrain. There is no consensus among authors, neither on the expression level of $N K X 2.1$ in cortical progenitors, nor on the role of $N K X 2.1$ in human cortical neurogenesis (Fig.4C,D) $[22,60,75,76]$. Recent extensive analyses in the human cortex at GW10-14, revealed an almost null percentage of KI67(+) cells among the DLX2(+) cortical cells, a result confirmed by BrdU labeling experiments in cultured forebrain slices [23]. Ma et al. [18] did not find NKX2.1(+) cortical progenitors. In contrast, Radonjic et al. [76] described a small percentage of NKX2.1(+) cells among cortical progenitors at GW15-22, which could well contribute to a significant population of cIN because of the large size of the oSVZ at this stage [76]. In vitro, NKX2.1 induces LHX6 expression in pallial progenitors, indicating their commitment to the PV and SST lineages. SHH application on cortical progenitors increases the pool expressing NKX2.1, at the expense of CR(+) cells [119]. Since the human cortex is remarkable by the increased proportion of $\mathrm{CR}(+)$ cIN, the putative contribution of cortical cIN progenitors to the PV/SST lineage is somehow puzzling and suggests an important role of the SHH signaling pathway in regulating the neurogenesis of $\mathrm{CR}(+) \mathrm{cIN}$ in the human cortex.

The suggestion of a pallial origin of cIN in the human cortex is further supported by the fact that $17 \%$ of the total number of $\mathrm{CR}(+)$ cells are co-labeled with KI67 antibodies in the oSVZ of the human cortex [22]. These dividing CR(+) cells either originate from the pallial precursors or come from the subpallium and undergo additional round of proliferation during their migration into the cortex $[22,60]$. Cells migrating from the GE to the cortex at early embryonic stages do not seem to divide ([118] and our own observations), although this possibility cannot be totally excluded. Indeed, it has been reported in the mouse that GAD65(+)CR(+) interneuron precursors derived from the CGE-LGE, can re-enter the cell cycle in the dorsal white matter after an initial phase of tangential migration [105]. Alternatively, the apparent pallial origin of certain olfactory interneurons [117] suggests that some cortical progenitors have the capacity to produce inhibitory neurons. And small numbers of mouse cIN are produced in the cortical SVZ after birth and completion of excitatory neuron production [116]. However, after an extensive search for the proliferative state of $\mathrm{CR}(+)$ interneurons in numerous cortical regions of human fetuses at GW10-14, Hansen et al. [23] concluded that virtually all cortical CR(+) and DLX2(+) inhibitory neuron precursors are non-proliferative in the human cortex.

The diverging conclusions discussed above should not hide that a major breakthrough was recently made by Hansen et al. [23], when they demonstrated a considerable increase in size of the primate CGE as compared with the CGE in rodents (illustrated in Fig.2E and Fig.3C). Other groups have confirmed this remarkable and novel observation [18,3]. Since the majority of CGE-derived cIN express $\mathrm{CR}$, the dramatic increase in $\mathrm{CR}(+) \mathrm{cIN}$ in the human cortex very likely results from the spectacular enlargement of the CGE. The number and diversity of GABAergic interneurons have increased concomitantly with the number of excitatory projection neurons so that a balance between excitatory and inhibitory activities was maintained in the human cortex $[111,112]$. In human and non-human primates, the 
production of an increased number of excitatory projection neurons is related to the emergence of a new proliferative compartment, the outer subventricular zone (oSVZ). Such a neurogenic extension occurred thanks to developmental changes particularly visible around midterm in human, when both oSVZ and CGE are particularly developed (Fig.1). It has to be mentioned that the enlargement of both oSVZ and CGE in humans has no equivalent in rodents [113-115] and likely represents a derived feature of primates.

\section{A conserved subpallial origin of cIN in all gnathostomes, and conserved migratory properties.}

Even if authors disagree on the regional origin of cIN during the late phase of neurogenesis in primates, most of them agree that the GEs are the main sources of GABAergic neurons during the first trimester of gestation in humans and until E55E65 in the Cynomolgus monkey $[22,60,108,109,114]$. Based on the continuity of temporal sequences of expression of GABA and of SOX6, COUP-TFII, SP8 transcription factors in the telencephalic vesicles, the studies of Ma et al. and Hansen et al. [18,23] show that the majority, if not all, GABAergic interneurons originate in the GEs in both human and non-human primates. These studies moreover reveal that developmental mechanisms responsible for the production of GABAergic interneurons are extremely well conserved in vertebrates [18,23].

The regionalization of the forebrain, with distinct domains marked by differential, specific gene expression patterns (or genoarchitecture), shows an impressive degree of conservation across all gnathostomes and might be dated back to more than 500 million years ago when the latest common ancestor of vertebrates arose [120-123].

Comparative analyses of orthologous genes expression in chick, turtle, frog, zebrafish or lamprey have shown that forebrain patterns are largely conserved among these species [122-127]. Thus, the basic developmental plan of the subpallium in the telencephalon has a deep evolutionary origin and the GE origin of cIN appears highly conserved in all Gnatosthomes [128-130].

In mice as in other mammalian species examined so far, the capability to migrate long distances tangentially to the brain surface toward the dorsal pallium is a cardinal property of the GABAergic lineage born in the basal forebrain. The first experiments that evidenced the long distance migration of cINs from the subpallium to the developing cortical plate, consisted of vital dye injections in organotypic slices of mouse embryos. Precursors of cIN labeled in the subpallium migrated long distances in the organotypic cortical slices and reached the cortex after one or two days in culture [25,26,103]. Analyses of the long distance migration of cIN precursors strongly benefited from the development of transgenic mouse strains that express fluorescent markers in cIN $[131,132]$. Live cell imaging of cIN expressing fluorescent proteins (such as GFP) in slices of embryonic cortex helped to identify the migratory routes of cIN within the cortical wall $[133,134]$. Immature cIN first enter the cortical wall by a tangential route located either superficially in the marginal zone (MZ) or deep in the SVZ/lower IZ. After the CP differentiates, an additional tangential route forms in the SP. cIN then reorient radially and move to the CP where they settle and differentiate (Fig.2D,2E). A proportion of cIN follows oblique trajectories rather than tangential ones, and the radial re-orientation can be directed toward the VZ rather 
than the CP. In various mammalian species examined so far (rat $[135,136]$, opossums [137], cynomolgus monkey [109]) as well as in the human brain $[22,61,138,139]$ GABAergic cIN migrate tangentially from the subpallium to the pallium via the MZ and SVZ/IZ routes (Fig.4), as described in the mouse. A tangential mode of migration is already present in infra mammals, in the chicken, turtle, sharks and lamprey where MGE cells migrate from the subpallium to the dorsal pallium along more or less well defined pathways $[126,127,140]$.

The intrinsic migratory ability of subpallium-derived GABAergic cIN was tested by interspecies transplantations. Ex vivo interspecies transplantations showed that turtle MGE cells transplanted into the mouse MGE migrated tangentially and entered the mouse neocortex, and vice versa [127], suggesting that the ability of MGE cells to enter the neocortical primordium had already been established in the most recent common ancestor of amniotes. In utero interspecies transplantation of chicken, turtle or marmoset MGE cells into the mouse MGE revealed that, in contrast to mouse and marmoset MGE cells, a majority of chicken and turtle MGE cells fail to enter the cortical plate and remain in the SVZ/IZ [130]. Nevertheless, 29 days after transplantation the chicken MGE cells had differentiated into GABAergic cIN within the mouse neocortex and expressed either PV or SST. Therefore, the intrinsic ability of MGE cells to generate both $\mathrm{PV}(+)$ and $\mathrm{SST}(+)$ cells is conserved in all amniotes.

\section{Migration routes of $\mathrm{cIN}$ in the human brain}

\subsection{Migration routes toward the cortex}

Dye injections in forebrain slices from human fetuses at GW15 [61] label a significant number of GE cells that migrated to the cortical VZ/SVZ (Fig.4f in [61]). This experimental approach is highly challenging in human, for ethical and technical reasons [18,23], notably because of the length, duration and complexity of cIN trajectories in the human cortex. Therefore, analyses in humans are restricted to small portions of cIN trajectories [139]. The analysis of cIN migratory pathways in the developing human brain thus essentially relies on neuroanatomical observations on fixed tissue using markers stably expressed in cIN, both spatially and temporally. GABA, GAD, SOX6, SP8 or COUP-TFII are stable and reliable markers of cIN (however not exclusive to cIN). Whereas SOX6, SP8 and COUP-TFII antibodies stain nuclei, GABA and GAD distribute in the whole cell including thin protrusions. GABA immunostaining reveals the morphology of cIN precisely enough to identify their polarity and their direction of migration. GABA immunostaining moreover reflects the activity of the glutamic acid decarboxylases (GAD), whose expression is activated by DLX proteins [65]. The two isoforms 65 and 67 (also known as Gad1) are co-expressed in almost all GABAergic neurons in the mouse, monkey and human adult brain[21,65,109].

Before genetic studies established that GABA and GAD are reliable ontogenic markers, careful and detailed descriptions of the distribution and morphology of cells expressing GABA and/or GAD had been performed in the developing cortex of both rodents and primates [109,141-146]. Authors took advantage of the polarized morphology of GABA neurons that exhibited growth cones at the end of long leading processes, for identifying the direction of movement of GABAergic neurons in the 
developing cortex. By correlating the putative directions of movement with the changes in distribution of the GABA neurons, authors inferred from analyses on fixed tissue that pioneer GABA cells have a lateral to medial direction of movement in the developing cortical wall. However, complex morphological changes associated with trajectories reorientation and transient polarity reversals are major limitations of these analyses on fixed tissue. The rodent subplate is a typical decision region were cIN exhibit complex morphologies, which had not been associated with trajectories reorientations in early studies [141,142]. In addition, the radial re-orientation of cIN away from their tangential routes of migration progressively hampers tangential streams of cIN in fixed sections and prevents analyses of the late stages of migration. Because GABA cells were found in two transient structures of the developing cortex, the cortical subplate and the marginal zone, it was initially proposed that GABAergic cells are pioneer cells that disappear with these transient structures.

In primates, the large size of structures and the long duration of developmental phases make the identification of streams of GABAergic cells easier than in rodents. GABAergic cells oriented tangentially (i.e. parallel) to the brain surface are organized in continuous and dense streams between the subpallium and pallium. A large stream of GABAergic cells was first described between the GE and the cortex in the rostral part of the telencephalic vesicles in human [22,60,61]. GABA and GAD65 immunostaining labeled similar migratory stream in the rostral telencephalon of the Cynomolgus Monkey [109]. In the human brain, Ma et al. [18] and Hansen et al. [23] have recently identified large streams of cells that express subpallial genes and extend between the GE and the developing cortex. Transcription factors expressed either in the MGE, or in the ventral and dorsal parts of the CGE label distinct migratory streams and identify different routes of migration between the GE and the cortex. Cells in streams usually do not express proliferation markers. Two main routes of migration have been described. NKX2.1(+) cells materialize the beginning of the route between the MGE and the cortex, which extend trough the LGE. SOX6, a stable marker of MGE-derived cells, identifies the end of the same route that crosses the LGE and reaches the lateral and anterior cortex. A second route of migration is identified by large and continuous streams of cells expressing COUP-TFII or SP8, which extend between the CGE and occipital cortical regions [18,23,75]. As in the mouse, interneurons from the CGE migrate caudally toward the hippocampus and the caudal cerebral cortex [44] under Coup-TFII control [84]. A study from Clowry and coll. in humans [75], shows different cortical distribution of cIN generated in distinct parts of the GE, strengthening previous observations of Ma et al [18], who found different ratios of CR and PV/SST cIN in the frontal and caudal cortex.

Doublecortin $(\mathrm{CDX})$ is another marker expressed in young migrating neurons in the human cortex [147], which reveals interneuron morphology. DCX recently helped to identify the directions of movement of a population of GABAergic neurons present at birth in the human frontal cortex. These neurons moreover express transcription factors identifying their ventral telencephalic origin, in particular SP8, COUP-TFII, NKX2.1, or LHX6 [139].

\subsection{Migration routes within the cortex}

\subsubsection{Embryonic and fetal stages}

In the human brain, the first GABAergic cells are observed at the surface of the cortical anlage at very early stage (GW6.5-7) when the cortical wall only comprises the proliferative neuroepithelium (VZ) and a superficial layer of post-mitotic cells, the 
plexiform layer (PPL, Fig.1) [21,138]. At this stage, GABAergic cells distribute in a latero-medial gradient. Most of them exhibit either bipolar or unipolar morphologies suggestive of migrating cells. They often extend tangentially to the brain surface one long process ending with a growth cone. Very few radially oriented GABA(+) cells are present in the VZ [60]. Radially oriented $\mathrm{GABA}(+)$ cells could either originate locally or, more likely, colonize the VZ from the superficial PPL using a ventricledirected migration as described in organotypic cortical slices from rodents [148,149]. Accordingly, some radial DLX2-expressing cells that co-express MAP2, a neuronal marker, are also observed in the $\mathrm{VZ}$ at same stage [60]. These neurons could migrate from the PPL/MZ that contains tangentially oriented cells co-expressing DLX2 and MAP2 (Fig.4A). Young DLX2(+) neurons likely migrate from the GE to the cortex as observed in the mouse.

As development proceeds, GABAergic cells become more numerous in the human cerebral wall and distribute between the $\mathrm{MZ}$ and the $\mathrm{VZ}$ in the developing $\mathrm{CP}$ (Fig. 4B). Regional differences in cell density are no longer observed at GW11. GABA(+) cells extend horizontal/tangential or oblique processes, and structures resembling growth cones are observed at the tip of the processes. From GW11, another population of tangentially oriented GABAergic cells appears in the lower part of the IZ and in the SVZ $[138,143]$. Some horizontally oriented GABA(+) cells distributes along the ventricle. GABAergic cells in the cortical VZ and SVZ express markers of young neurons (TUJ1, MAP2) showing that they are post-mitotic immature neurons extending long processes parallel to the surface of the ventricle.

This early distribution and laminar location of GABAergic cells corresponds well to the distribution in rodents and nonhuman primates [150,151]. In the CP, GABAergic cells exhibit preponderant radial orientation suggesting that they use both radial and tangential migration to disperse in the developing cortex [138].

From GW14 to midterm [22,143] (Fig.4C), the density of GABAergic cells increases in the SVZ/IZ, SP and MZ. Authors report variable orientations of process, but agree on a large proportion of tangentially oriented cells in the VZ, IZ and oSVZ. In the IZ and SP, horizontal processes intersect radially orientated GABAergic cells. At these stage, the distribution, morphology and orientation of $\mathrm{CR}(+)$ cells is reminiscent of GABAergic cells (Fig.4C) [22].

During the second half of the gestation (Fig.4D), the peak of GABA immunoreactivity moves superficially in the developing $\mathrm{CP}$, where the proportion of multipolar cells increases in comparison with bipolar GABAergic cells [143].

In the Cynomolgus Monkey, a similar sequence of development is observed for GAD65-expressing (GAD65(+)) cells [109]. A large stream of tangentially oriented GAD65(+) cells distributes in the lower IZ/upper SVZ of all cortical regions at E55 (equivalent of GW13/14 in human). Smaller streams of GAD65(+) cells are also observed in the MZ and SP. At a stage corresponding to midterm in human, GAD65(+) are numerous in the VZ/SVZ and GAD65(+) cells lacking the horizontal orientation observed at early stages, distribute in the whole thickness of the cortical wall. 


\subsubsection{Post-natal migration of cIN}

Neuronal migration is considered to be largely complete before birth, except for specific population of GABAergic interneurons that contributes to the olfactory bulb and, in a limited extent, to the anterior forebrain [152]. Throughout life, neural stem cells in different domains of the SVZ of the adult rodent brain generate several subtypes of interneurons that travel from the walls of the lateral ventricle, along the rostral migratory stream (RMS) and add to circuits into the olfactory bulb $[153,154]$. In humans, a sub-population of young SVZ-derived neurons migrate along a ventral route branching off the RMS, the medial migratory stream (MMS) and settle in the medial prefrontal cortex [154]. At birth in human neonates, although many SP8(+) and/or COUP-TFII(+) cells already reached the superficial cortical layers, some of them are still present in the cortical SVZ [18], suggesting that their migration to the cortex continues during infancy $[139,154]$. Post-mortem analyses in infant human brains have recently established that a large population of young neurons still migrates at birth in the frontal lobe of the cortex [139]. This population will integrate the frontal cortex during the first months of post-natal life These young neurons express DCX and GABA, but neither progenitors no pallial markers. Most of them express subpallial markers showing that they likely originate in the CGE, MGE, and possibly LGE. They concentrate at birth in the anterior horn of the lateral ventricle, where they distribute along the ventricle and blood vessels in an arc-shaped structure. Infection of tissue with GFP-expressing adenovirus reveals that these cells migrate using a saltatory mode of progression identical to the mode of migration of GABAergic neurons in the embryonic cortex $[133,155,156]$. Near the ventricle, cell trajectories are predominantly tangential to the brain surface. Within the cortical parenchyma, young neurons reorient their trajectories perpendicular to the cortical layers [139].

These novel data, by showing that a pool of young post mitotic neurons are stored in tangential migratory streams after birth, suggest that cIN can be integrated postnatally in perhaps fully functional circuits. This opens new avenues for understanding the clinical consequences of perinatal strokes and experiencedependent functional maturation of the cortex.

\section{Conclusion}

cIN are implicated in a wide range of neuropsychiatric disorders as epilepsy, bipolar disorders, attention deficit hyperactivity disorder (ADHD), schizophrenia and autism. The heterogeneity of cIN and their complex and long-lasting phase of migration could make them particularly sensitive to a wide variety of intrinsic (genetic) and extrinsic (environmental, functional, ...) factors that can alter their development and lead to defective cortical circuits. For example, dysfunction or cell death of specific types of GABAergic neurons has been described as a hallmark of various psychiatric and neurological disorders, such as schizophrenia and epilepsy. Several studies associate dysfunction of $\mathrm{PV}(+)$ interneurons in frontal cortex with schizophrenia [157-160]. Neocortical interneurons in the upper layers are believed to be involved in the physiopathology of these psychiatric disorders [161]. For example, the specific removal of Lhx6 and Sox6 from MGE-derived cIN leads to abnormal PV and SST expression related to mispositioning of basket and Martinotti cIN. As a 
consequence, this results in a severe epileptic encephalopathy [162]. An imbalance between excitation and inhibition in the cerebral cortex has also been suggested as a possible etiology of autism [163]. Interestingly, $D L X 1 \& 2$ polymorphism is associated with autism [164]. Beside genetic mutations, intracerebral hemorrhage observed in the cortical SVZ in premature babies and neonates [165] may have serious consequences on later brain development. Hemorrhage can destroy a large number of interneurons and oligodendrocytes destined for the cerebral cortex and still located in the tangential migratory streams [166]. By depleting neonate or preterm brains in cIN, intracerebral hemorrhage could be implicated in schizophrenia and in neuropsychiatric disorders resulting form alteration in the excitation/inhibition balance [167]. The recent study of Paredes et al. [139], by opening a new and previously unexpected chapter of the biology of interneurons in the human cortex, give us a glimpse of a potential cell-based therapy in the treatment of neurological disorders, even if any plan to correct brain activity should be based on a stronger knowledge on the normal and pathological human brain development. Although caution should be the rule with mouse-human extrapolations [3], it remains that the power of genetic studies in mouse models is considerable and served well our increasing knowledge of the human brain development. Studies in the mouse are at the origin of the recent highlight on a large territory in the human basal forebrain that expresses CGE specific genes and likely contributes the numerically and functionally important population of CR-expressing cIN in humans. Reciprocally, incoming observations in humans should provide valuable insight to further understand the mouse model and the regional differences in the migration and maturation of cortical interneurons. 
References

[1] M.R. del Río, J. DeFelipe, Colocalization of calbindin D-28k, calretinin, and GABA immunoreactivities in neurons of the human temporal cortex, J. Comp. Neurol. 369 (1996) 472-482. doi:10.1002/(SICI)10969861(19960603)369:3\&lt;472::AID-CNE11\&gt;3.0.CO;2-K.

[2] J. DeFelipe, The evolution of the brain, the human nature of cortical circuits, and intellectual creativity, Front Neuroanat. 5 (2011) 29. doi:10.3389/fnana.2011.00029.

[3] G.J. Clowry, An enhanced role and expanded developmental origins for gamma-aminobutyric acidergic interneurons in the human cerebral cortex, Journal of Anatomy. 227 (2015) 384-393. doi:10.1111/joa.12198.

[4] C.J. McBain, A. Fisahn, Interneurons unbound, Nat Rev Neurosci. 2 (2001) 11-23. doi:10.1038/35049047.

[5] H. Markram, M. Toledo-Rodriguez, Y. Wang, A. Gupta, G. Silberberg, C. Wu, Interneurons of the neocortical inhibitory system, Nat Rev Neurosci. 5 (2004) 793-807. doi:10.1038/nrn1519.

[6] G.A. Ascoli, L. Alonso-Nanclares, S.A. Anderson, G. Barrionuevo, R. Benavides-Piccione, A. Burkhalter, et al., Petilla terminology: nomenclature of features of GABAergic interneurons of the cerebral cortex, Nat Rev Neurosci. 9 (2008) 557-568. doi:10.1038/nrn2402.

[7] R. Batista-Brito, E. Rossignol, J. Hjerling-Leffler, M. Denaxa, M. Wegner, V. Lefebvre, et al., The Cell-Intrinsic Requirement of Sox6 for Cortical Interneuron Development, Neuron. 63 (2009) 466-481. doi:10.1016/j.neuron.2009.08.005.

[8] J. DeFelipe, P.L. López-Cruz, R. Benavides-Piccione, C. Bielza, P. Larrañaga, S. Anderson, et al., New insights into the classification and nomenclature of cortical GABAergic interneurons, (2013) 1-15. doi:10.1038/nrn3444.

[9] R. Tremblay, S. Lee, B. Rudy, GABAergic Interneurons in the Neocortex: From Cellular Properties to Circuits, Neuron. 91 (2016) 260292. doi:10.1016/j.neuron.2016.06.033.

[10] B. Wamsley, G. Fishell, Genetic and activity-dependent mechanisms underlying interneuron diversity, Nature Cell Biology. 18 (2017) 299309. doi:10.1038/nrn.2017.30.

[11] B. Tasic, V. Menon, T.N. Nguyen, T.K. Kim, T. Jarsky, Z. Yao, et al., Adult mouse cortical cell taxonomy revealed by single cell transcriptomics, Nature Neuroscience. 19 (2016) 335-346. doi:10.1038/nn.4216.

[12] A. Zeisel, A.B. Munoz-Manchado, S. Codeluppi, P. Lonnerberg, G. La Manno, A. Jureus, et al., Cell types in the mouse cortex and hippocampus revealed by single-cell RNA-seq, Science. 347 (2015) 1138-1142. doi:10.1126/science.aaa1934.

[13] J.L. Close, Z. Yao, B.P. Levi, J.A. Miller, T.E. Bakken, V. Menon, et al., Single-Cell Profiling of an In Vitro Model of Human Interneuron Development Reveals Temporal Dynamics of Cell Type Production and Maturation, Neuron. $93 \quad$ (2017) 1035-1048.e5. doi:10.1016/j.neuron.2017.02.014.

[14] S. Lee, J. Hjerling-Leffler, E. Zagha, G. Fishell, B. Rudy, The largest group of superficial neocortical GABAergic interneurons expresses 
ionotropic serotonin receptors, Journal of Neuroscience. 30 (2010) 16796-16808. doi:10.1523/JNEUROSCI.1869-10.2010.

[15] G. Fishell, B. Rudy, Mechanisms of inhibition within the telencephalon: "where the wild things are", Annu. Rev. Neurosci. 34 (2011) 535-567. doi:10.1146/annurev-neuro-061010-113717.

[16] G. Miyoshi, J. Hjerling-Leffler, T. Karayannis, V.H. Sousa, S.J.B. Butt, J. Battiste, et al., Genetic fate mapping reveals that the caudal ganglionic eminence produces a large and diverse population of superficial cortical interneurons, Journal of Neuroscience. 30 (2010) 1582-1594. doi:10.1523/JNEUROSCI.4515-09.2010.

[17] Q. Xu, L. Guo, H. Moore, R.R. Waclaw, K. Campbell, S.A. Anderson, Sonic Hedgehog Signaling Confers Ventral Telencephalic Progenitorswith Distinct Cortical Interneuron Fates, Neuron. 65 (2010) 328-340. doi:10.1016/j.neuron.2010.01.004.

[18] T. Ma, C. Wang, L. Wang, X. Zhou, M. Tian, Q. Zhang, et al., Subcortical origins of human and monkey neocortical interneurons, Nature Neuroscience. 16 (2013) 1588-1597. doi:10.1038/nn.3536.

[19] X.X. Yan, Q.L. Cao, X.G. Luo, L.J. Garey, Prenatal development of calbindin D-28K in human visual cortex, Cereb. Cortex. 7 (1997) 57-62.

[20] N. Zecevic, A. Milosevic, S. Rakic, M. Marín-Padilla, Early development and composition of the human primordial plexiform layer: An immunohistochemical study, J. Comp. Neurol. 412 (1999) 241-254.

[21] G. Meyer, J.P. Schaaps, L. Moreau, A.M. Goffinet, Embryonic and early fetal development of the human neocortex, Journal of Neuroscience. 20 (2000) 1858-1868.

[22] N. Zecevic, F. Hu, I. Jakovcevski, Interneurons in the developing human neocortex, Devel Neurobio. 71 (2011) 18-33. doi:10.1002/dneu.20812.

[23] D.V. Hansen, J.H. Lui, P. Flandin, K. Yoshikawa, J.L. Rubenstein, A. Alvarez-Buylla, et al., Non-epithelial stem cells and cortical interneuron production in the human ganglionic eminences, Nature Neuroscience. 16 (2013) 1576-1587. doi:10.1038/nn.3541.

[24] Z. Molnár, S.J.B. Butt, Best-laid schemes for interneuron origin of mice and men, Nature Neuroscience. $16 \quad$ (2013) 1512-1514. doi:10.1038/nn.3557.

[25] S.A. Anderson, D.D. Eisenstat, L. Shi, J.L. Rubenstein, Interneuron migration from basal forebrain to neocortex: dependence on Dlx genes, Science. 278 (1997) 474-476.

[26] N. Tamamaki, K.E. Fujimori, R. Takauji, Origin and route of tangentially migrating neurons in the developing neocortical intermediate zone, J. Neurosci. 17 (1997) 8313-8323.

[27] A.A. Lavdas, M. Grigoriou, V. Pachnis, J.G. Parnavelas, The medial ganglionic eminence gives rise to a population of early neurons in the developing cerebral cortex, Journal of Neuroscience. 19 (1999) 78817888.

[28] H. Wichterle, J.M. García-Verdugo, D.G. Herrera, A. Alvarez-Buylla, Young neurons from medial ganglionic eminence disperse in adult and embryonic brain, Nature Neuroscience. 2 (1999) 461-466.

[29] S.A. Anderson, O. Marin, C. Horn, K. Jennings, J.L. Rubenstein, Distinct cortical migrations from the medial and lateral ganglionic eminences, Development. 128 (2001) 353-363. 
[30] H. Wichterle, D.H. Turnbull, S. Nery, G. Fishell, A. Alvarez-Buylla, In utero fate mapping reveals distinct migratory pathways and fates of neurons born in the mammalian basal forebrain, Development. 128 (2001) 3759-3771.

[31] J.G. Parnavelas, The origin and migration of cortical neurones: new vistas, Trends in Neurosciences. 23 (2000) 126-131.

[32] O. Marin, J.L. Rubenstein, A long, remarkable journey: tangential migration in the telencephalon, Nat Rev Neurosci. 2 (2001) 780-790. doi: $10.1038 / 35097509$.

[33] J.G. Parnavelas, P. Alifragis, B. Nadarajah, The origin and migration of cortical neurons, Prog. Brain Res. 136 (2002) 73-80.

[34] C. Métin, J.-P. Baudoin, S. Rakic, J.G. Parnavelas, Cell and molecular mechanisms involved in the migration of cortical interneurons, European Journal of Neuroscience. 23 (2006) 894-900. doi:10.1111/j.14609568.2006.04630.x.

[35] N. Kessaris, M. Fogarty, P. Iannarelli, M. Grist, M. Wegner, W.D. Richardson, Competing waves of oligodendrocytes in the forebrain and postnatal elimination of an embryonic lineage, Nature Neuroscience. 9 (2006) 173-179. doi:10.1038/nn1620.

[36] Q. Xu, M. Tam, S.A. Anderson, Fate mapping Nkx2.1-lineage cells in the mouse telencephalon, J. Comp. Neurol. 506 (2008) 16-29. doi:10.1002/cne.21529.

[37] L. Puelles, J.L.R. Rubenstein, Expression patterns of homeobox and other putative regulatory genes in the embryonic mouse forebrain suggest a neuromeric organization, Trends in Neurosciences. 16 (1993) 472-479. doi:10.1016/0166-2236(93)90080-6.

[38] H. Valcanis, S.-S. Tan, Layer specification of transplanted interneurons in developing mouse neocortex, Journal of Neuroscience. 23 (2003) 5113-5122.

[39] D. Gelman, A. Griveau, N. Dehorter, A. Teissier, C. Varela, R. Pla, et al., A wide diversity of cortical GABAergic interneurons derives from the embryonic preoptic area, Journal of Neuroscience. 31 (2011) 1657016580. doi:10.1523/JNEUROSCI.4068-11.2011.

[40] Q. Xu, I. Cobos, E. de la Cruz, J.L. Rubenstein, S.A. Anderson, Origins of cortical interneuron subtypes, Journal of Neuroscience. 24 (2004) 2612-2622. doi:10.1523/JNEUROSCI.5667-03.2004.

[41] S.J.B. Butt, M. Fuccillo, S. Nery, S. Noctor, A. Kriegstein, J.G. Corbin, et al., The Temporal and Spatial Origins of Cortical Interneurons Predict Their Physiological Subtype, Neuron. 48 (2005) 591-604. doi:10.1016/j.neuron.2005.09.034.

[42] M. Fogarty, M. Grist, D. Gelman, O. Marín, V. Pachnis, N. Kessaris, Spatial genetic patterning of the embryonic neuroepithelium generates GABAergic interneuron diversity in the adult cortex, Journal of Neuroscience. 27 (2007) 10935-10946. doi:10.1523/JNEUROSCI.162907.2007.

[43] G. Miyoshi, S.J.B. Butt, H. Takebayashi, G. Fishell, Physiologically Distinct Temporal Cohorts of Cortical Interneurons Arise from Telencephalic Olig2-Expressing Precursors, Journal of Neuroscience. 27 (2007) 7786-7798. doi:10.1523/JNEUROSCI.1807-07.2007.

[44] S. Nery, G. Fishell, J.G. Corbin, The caudal ganglionic eminence is a 
source of distinct cortical and subcortical cell populations, Nature Neuroscience. 5 (2002) 1279-1287. doi:10.1038/nn971.

[45] P. Larimer, J. Spatazza, J.S. Espinosa, Y. Tang, M. Kaneko, A.R. Hasenstaub, et al., Caudal Ganglionic Eminence Precursor Transplants Disperse and Integrate as Lineage-Specific Interneurons but Do Not Induce Cortical Plasticity, CellReports. 16 (2016) 1391-1404. doi:10.1016/j.celrep.2016.06.071.

[46] S. Anderson, M. Mione, K. Yun, J.L. Rubenstein, Differential origins of neocortical projection and local circuit neurons: role of Dlx genes in neocortical interneuronogenesis, Cereb. Cortex. 9 (1999) 646-654.

[47] S. Casarosa, C. Fode, F. Guillemot, Mash1 regulates neurogenesis in the ventral telencephalon, Development. 126 (1999) 525-534.

[48] S. Horton, A. Meredith, J.A. Richardson, J.E. Johnson, Correct coordination of neuronal differentiation events in ventral forebrain requires the bHLH factor MASH1, Mol Cell Neurosci. 14 (1999) 355369. doi:10.1006/mone.1999.0791.

[49] J.E. Long, S. Garel, M. Alvarez-Dolado, K. Yoshikawa, N. Osumi, A. Alvarez-Buylla, et al., Dlx-dependent and -independent regulation of olfactory bulb interneuron differentiation, Journal of Neuroscience. 27 (2007) 3230-3243. doi:10.1523/JNEUROSCI.5265-06.2007.

[50] J.E. Long, C. Swan, W.S. Liang, I. Cobos, G.B. Potter, J.L.R. Rubenstein, Dlx1\&2 and Mash1 transcription factors control striatal patterning and differentiation through parallel and overlapping pathways, J. Comp. Neurol. 512 (2009) 556-572. doi:10.1002/cne.21854.

[51] K. Yun, S. Fischman, J. Johnson, M. Hrabe de Angelis, G. Weinmaster, J.L.R. Rubenstein, Modulation of the notch signaling by Mash1 and Dlx1/2 regulates sequential specification and differentiation of progenitor cell types in the subcortical telencephalon, Development. 129 (2002) 5029-5040.

[52] C. Schuurmans, F. Guillemot, Molecular mechanisms underlying cell fate specification in the developing telencephalon, Current Opinion in Neurobiology. 12 (2002) 26-34.

[53] M.A. Petryniak, G.B. Potter, D.H. Rowitch, J.L.R. Rubenstein, Dlx1 and Dlx2 control neuronal versus oligodendroglial cell fate acquisition in the developing forebrain, Neuron. 55 (2007) 417-433. doi:10.1016/j.neuron.2007.06.036.

[54] C.M. Parras, C. Hunt, M. Sugimori, M. Nakafuku, D. Rowitch, F. Guillemot, The proneural gene Mash1 specifies an early population of telencephalic oligodendrocytes, Journal of Neuroscience. 27 (2007) 4233-4242. doi:10.1523/JNEUROSCI.0126-07.2007.

[55] C. Fode, Q. Ma, S. Casarosa, S.L. Ang, D.J. Anderson, F. Guillemot, A role for neural determination genes in specifying the dorsoventral identity of telencephalic neurons, Genes \& Development. 14 (2000) 67-80.

[56] J.G. Corbin, M. Rutlin, N. Gaiano, G. Fishell, Combinatorial function of the homeodomain proteins $\mathrm{Nkx} 2.1$ and Gsh2 in ventral telencephalic patterning, Development. $130 \quad$ (2003) 4895-4906. doi:10.1242/dev.00717.

[57] N. Flames, R. Pla, D.M. Gelman, J.L.R. Rubenstein, L. Puelles, O. Marín, Delineation of multiple subpallial progenitor domains by the combinatorial expression of transcriptional codes, Journal of 
Neuroscience. 27 (2007) 9682-9695. doi:10.1523/JNEUROSCI.275007.2007.

[58] T. Stühmer, S.A. Anderson, M. Ekker, J.L.R. Rubenstein, Ectopic expression of the Dlx genes induces glutamic acid decarboxylase and Dlx expression, Development. 129 (2002) 245-252.

[59] S. Nery, J.G. Corbin, G. Fishell, Dlx2 progenitor migration in wild type and Nkx2.1 mutant telencephalon, Cereb. Cortex. 13 (2003) 895-903.

[60] S. Rakic, N. Zecevic, Emerging complexity of layer I in human cerebral cortex, Cereb. Cortex. 13 (2003) 1072-1083.

[61] K. Letinic, R. Zoncu, P. Rakic, Origin of GABAergic neurons in the human neocortex, Nature. 417 (2002) 645-649.

[62] G.B. Potter, M.A. Petryniak, E. Shevchenko, G.L. McKinsey, M. Ekker, J.L.R. Rubenstein, Generation of Cre-transgenic mice using Dlx1/Dlx2 enhancers and their characterization in GABAergic interneurons, Mol Cell Neurosci. 40 (2009) 167-186. doi:10.1016/j.mcn.2008.10.003.

[63] R.B. MacDonald, M. Debiais-Thibaud, J.C. Talbot, M. Ekker, The relationship between dlx and gad1 expression indicates highly conserved genetic pathways in the zebrafish forebrain, Dev. Dyn. 239 (2010) 22982306. doi:10.1002/dvdy.22365.

[64] T. Du, Q. Xu, P.J. Ocbina, S.A. Anderson, NKX2.1 specifies cortical interneuron fate by activating Lhx6, Development. 135 (2008) 15591567. doi:10.1242/dev.015123.

[65] D.D. Eisenstat, J.K. Liu, M. Mione, W. Zhong, G. Yu, S.A. Anderson, et al., DLX-1, DLX-2, and DLX-5 expression define distinct stages of basal forebrain differentiation, J. Comp. Neurol. 414 (1999) 217-237.

[66] L. Sussel, O. Marin, S. Kimura, J.L. Rubenstein, Loss of Nkx2.1 homeobox gene function results in a ventral to dorsal molecular respecification within the basal telencephalon: evidence for a transformation of the pallidum into the striatum, Development. 126 (1999) 3359-3370.

[67] D.M. Gelman, F.J. Martini, S. Nobrega-Pereira, A. Pierani, N. Kessaris, O. Marin, The Embryonic Preoptic Area Is a Novel Source of Cortical GABAergic Interneurons, Journal of Neuroscience. 29 (2009) 93809389. doi:10.1523/JNEUROSCI.0604-09.2009.

[68] J.M. Hébert, G. Fishell, The genetics of early telencephalon patterning: some assembly required, Nat Rev Neurosci. 9 (2008) 678-685. doi:10.1038/nrn2463.

[69] Q. Xu, C.P. Wonders, S.A. Anderson, Sonic hedgehog maintains the identity of cortical interneuron progenitors in the ventral telencephalon, Development. 132 (2005) 4987-4998. doi:10.1242/dev.02090.

[70] C.P. Wonders, S.A. Anderson, The origin and specification of cortical interneurons, Nat Rev Neurosci. 7 (2006) 687-696. doi:10.1038/nrn1954.

[71] J.A. Tyson, E.M. Goldberg, A.M. Maroof, Q. Xu, T.J. Petros, S.A. Anderson, Duration of culture and sonic hedgehog signaling differentially specify PV versus SST cortical interneuron fates from embryonic stem cells, Development. 142 (2015) 1267-1278. doi:10.1242/dev.111526.

[72] E.M. DeBoer, S.A. Anderson, Fate determination of cerebral cortical GABAergic interneurons and their derivation from stem cells, Brain Research. 1655 (2017) 277-282. doi:10.1016/j.brainres.2015.12.031. 
[73] S.J.B. Butt, V.H. Sousa, M.V. Fuccillo, J. Hjerling-Leffler, G. Miyoshi, S. Kimura, et al., The Requirement of Nkx2-1 in the Temporal Specification of Cortical Interneuron Subtypes, Neuron. 59 (2008) $722-$ 732. doi:10.1016/j.neuron.2008.07.031.

[74] S. Nóbrega-Pereira, N. Kessaris, T. Du, S. Kimura, S.A. Anderson, O. Marín, Postmitotic Nkx2-1 controls the migration of telencephalic interneurons by direct repression of guidance receptors, Neuron. 59 (2008) 733-745. doi:10.1016/j.neuron.2008.07.024.

[75] A. Alzu'bi, S. Lindsay, J. Kerwin, S.J. Looi, F. Khalil, G.J. Clowry, Distinct cortical and sub-cortical neurogenic domains for GABAergic interneuron precursor transcription factors NKX2.1, OLIG2 and COUPTFII in early fetal human telencephalon, Brain Struct Funct. 25 (2016) 120. doi:10.1007/s00429-016-1343-5.

[76] N.V. Radonjić, A.E. Ayoub, F. Memi, X. Yu, A. Maroof, I. Jakovcevski, et al., Diversity of Cortical Interneurons in Primates: The Role of the Dorsal Proliferative Niche, CellReports. 9 (2014) 2139-2151. doi:10.1016/j.celrep.2014.11.026.

[77] M. Grigoriou, A.S. Tucker, P.T. Sharpe, V. Pachnis, Expression and regulation of Lhx6 and Lhx7, a novel subfamily of LIM homeodomain encoding genes, suggests a role in mammalian head development, Development. 125 (1998) 2063-2074.

[78] P. Liodis, M. Denaxa, M. Grigoriou, C. Akufo-Addo, Y. Yanagawa, V. Pachnis, Lhx6 activity is required for the normal migration and specification of cortical interneuron subtypes, Journal of Neuroscience. 27 (2007) 3078-3089. doi:10.1523/JNEUROSCI.3055-06.2007.

[79] Y. Zhao, P. Flandin, J.E. Long, M.D. Cuesta, H. Westphal, J.L.R. Rubenstein, Distinct molecular pathways for development of telencephalic interneuron subtypes revealed through analysis of Lhx6 mutants, J. Comp. Neurol. 510 (2008) 79-99. doi:10.1002/cne.21772.

[80] P. Alifragis, Lhx6 Regulates the Migration of Cortical Interneurons from the Ventral Telencephalon But Does Not Specify their GABA Phenotype, Journal of Neuroscience. 24 (2004) 5643-5648. doi:10.1523/JNEUROSCI.1245-04.2004.

[81] P. Flandin, S. Kimura, J.L.R. Rubenstein, The Progenitor Zone of the Ventral Medial Ganglionic Eminence Requires Nkx2-1 to Generate Most of the Globus Pallidus But Few Neocortical Interneurons, Journal of Neuroscience. 30 (2010) 2812-2823. doi:10.1523/JNEUROSCI.422809.2010.

[82] D. Vogt, R.F. Hunt, S. Mandal, M. Sandberg, S.N. Silberberg, T. Nagasawa, et al., Lhx6 Directly Regulates Arx and CXCR7 to Determine Cortical Interneuron Fate and Laminar Position, Neuron. 82 (2014) 350364. doi:10.1016/j.neuron.2014.02.030.

[83] E. Azim, D. Jabaudon, R.M. Fame, J.D. Macklis, SOX6 controls dorsal progenitor identity and interneuron diversity during neocortical development, Nature Neuroscience. 12 (2009) 1238-1247. doi:10.1038/nn.2387.

[84] S. Kanatani, M. Yozu, H. Tabata, K. Nakajima, COUP-TFII Is Preferentially Expressed in the Caudal Ganglionic Eminence and Is Involved in the Caudal Migratory Stream, Journal of Neuroscience. 28 (2008) 13582-13591. doi:10.1523/JNEUROSCI.2132-08.2008. 
S. Lodato, G.S. Tomassy, E. De Leonibus, Y.G. Uzcategui, G. Andolfi, M. Armentano, et al., Loss of COUP-TFI alters the balance between caudal ganglionic eminence- and medial ganglionic eminence-derived cortical interneurons and results in resistance to epilepsy, Journal of Neuroscience. 31 (2011) 4650-4662. doi:10.1523/JNEUROSCI.658010.2011 .

[86] G. Miyoshi, A. Young, T. Petros, T. Karayannis, M. McKenzie Chang, A. Lavado, et al., Prox1 Regulates the Subtype-Specific Development of Caudal Ganglionic Eminence-Derived GABAergic Cortical Interneurons, Journal of Neuroscience. $35 \quad$ (2015) 12869-12889. doi:10.1523/JNEUROSCI.1164-15.2015.

[87] J. Stenman, R.T. Yu, R.M. Evans, K. Campbell, Tlx and Pax6 co-operate genetically to establish the pallio-subpallial boundary in the embryonic mouse telencephalon, Development. 130 (2003) 1113-1122.

[88] A.N. Rubin, F. Alfonsi, M.P. Humphreys, C.K.P. Choi, S.F. Rocha, N. Kessaris, The germinal zones of the basal ganglia but not the septum generate GABAergic interneurons for the cortex, Journal of Neuroscience. 30 (2010) 12050-12062. doi:10.1523/JNEUROSCI.617809.2010 .

[89] L. Tricoire, K.A. Pelkey, M.I. Daw, V.H. Sousa, G. Miyoshi, B. Jeffries, et al., Common Origins of Hippocampal Ivy and Nitric Oxide Synthase Expressing Neurogliaform Cells, Journal of Neuroscience. 30 (2010) 2165-2176. doi:10.1523/JNEUROSCI.5123-09.2010.

[90] I. Férézou, B. Cauli, E.L. Hill, J. Rossier, E. Hamel, B. Lambolez, 5-HT3 receptors mediate serotonergic fast synaptic excitation of neocortical vasoactive intestinal peptide/cholecystokinin interneurons, Journal of Neuroscience. 22 (2002) 7389-7397.

[91] B. Rudy, G. Fishell, S. Lee, J. Hjerling-Leffler, Three groups of interneurons account for nearly $100 \%$ of neocortical GABAergic neurons, Devel Neurobio. 71 (2010) 45-61. doi:10.1002/dneu.20853.

[92] S. Murthy, M. Niquille, N. Hurni, G. Limoni, S. Frazer, P. Chameau, et al., Serotonin receptor $3 \mathrm{~A}$ controls interneuron migration into the neocortex, Nature Communications. 5 (2014) 5524. doi:10.1038/ncomms6524.

[93] M. Tripodi, A. Filosa, M. Armentano, M. Studer, The COUP-TF nuclear receptors regulate cell migration in the mammalian basal forebrain, Development. 131 (2004) 6119-6129. doi:10.1242/dev.01530.

[94] C. Varga, G. Tamás, P. Barzo, S. Olah, P. Somogyi, Molecular and Electrophysiological Characterization of GABAergic Interneurons Expressing the Transcription Factor COUP-TFII in the Adult Human Temporal Cortex, Cereb. Cortex. 25 (2015) 4430-4449. doi:10.1093/cercor/bhv045.

[95] T. Ma, Q. Zhang, Y. Cai, Y. You, J.L.R. Rubenstein, Z. Yang, A Subpopulation of Dorsal Lateral/Caudal Ganglionic Eminence-Derived Neocortical Interneurons Expresses the Transcription Factor Sp8, Cereb. Cortex. 22 (2012) 2120-2130. doi:10.1093/cercor/bhr296.

[96] R.R. Waclaw, Z.J. Allen, S.M. Bell, F. Erdélyi, G. Szabo, S.S. Potter, et al., The zinc finger transcription factor Sp8 regulates the generation and diversity of olfactory bulb interneurons, Neuron. 49 (2006) 503-516. doi:10.1016/j.neuron.2006.01.018. 
[97] H. Toresson, S.S. Potter, K. Campbell, Genetic control of dorsal-ventral identity in the telencephalon: opposing roles for Pax6 and Gsh2, Development. 127 (2000) 4361-4371.

[98] K. Yun, S. Potter, J.L. Rubenstein, Gsh2 and Pax6 play complementary roles in dorsoventral patterning of the mammalian telencephalon, Development. 128 (2001) 193-205.

[99] K. Yun, S. Garel, S. Fischman, J.L.R. Rubenstein, Patterning of the lateral ganglionic eminence by the Gsh1 and Gsh2 homeobox genes regulates striatal and olfactory bulb histogenesis and the growth of axons through the basal ganglia, J. Comp. Neurol. 461 (2003) 151-165. doi:10.1002/cne.10685.

[100] A. Zembrzycki, G. Griesel, A. Stoykova, A. Mansouri, Genetic interplay between the transcription factors Sp8 and Emx2 in the patterning of the forebrain, Neural Development. 2 (2007) 8-18. doi:10.1186/1749-81042-8.

[101] Y. Cai, Q. Zhang, C. Wang, Y. Zhang, T. Ma, X. Zhou, et al., Nuclear receptor COUP-TFII-expressing neocortical interneurons are derived from the medial and lateral/caudal ganglionic eminence and define specific subsets of mature interneurons, J. Comp. Neurol. 521 (2012) 479-497. doi:10.1002/cne.23186.

[102] F. Bielle, A. Griveau, N. Narboux-Nême, S. Vigneau, M. Sigrist, S. Arber, et al., Multiple origins of Cajal-Retzius cells at the borders of the developing pallium, Nature Neuroscience. 8 (2005) 1002-1012. doi:10.1038/nn1511.

[103] J.A. de Carlos, L. López-Mascaraque, F. Valverde, Dynamics of cell migration from the lateral ganglionic eminence in the rat, J. Neurosci. 16 (1996) 6146-6156.

[104] D. Jiménez, L.M. López-Mascaraque, F. Valverde, J.A. De Carlos, Tangential migration in neocortical development, Developmental Biology. 244 (2002) 155-169. doi:10.1006/dbio.2002.0586.

[105] O. Riccio, S. Murthy, G. Szabo, L. Vutskits, J.Z. Kiss, T. Vitalis, et al., New Pool of Cortical Interneuron Precursors in the Early Postnatal Dorsal White Matter, Cerebral Cortex. 22 (2011) 86-98. doi:10.1093/cercor/bhr086.

[106] Y. Cai, Y. Zhang, Q. Shen, J.L.R. Rubenstein, Z. Yang, A Subpopulation of Individual Neural Progenitors in the Mammalian Dorsal Pallium Generates Both Projection Neurons and Interneurons In Vitro, Stem Cells. 31 (2013) 1193-1201. doi:10.1002/stem.1363.

[107] A.N. Rubin, N. Kessaris, PROX1: a lineage tracer for cortical interneurons originating in the lateral/caudal ganglionic eminence and $\begin{array}{llllll}\text { preoptic area, PLoS ONE. } 8 & \text { (2013) } & \text { e77339. }\end{array}$ doi:10.1371/journal.pone.0077339.

[108] I. Jakovcevski, N. Mayer, N. Zecevic, Multiple origins of human neocortical interneurons are supported by distinct expression of transcription factors, Cerebral Cortex. 21 (2011) 1771-1782. doi:10.1093/cercor/bhq245.

[109] Z. Petanjek, B. Berger, M. Esclapez, Origins of Cortical GABAergic Neurons in the Cynomolgus Monkey, Cereb. Cortex. 19 (2009) 249-262. doi:10.1093/cercor/bhn078.

[110] S. Fertuzinhos, Z. Krsnik, Y.I. Kawasawa, M.-R. Rašin, K.Y. Kwan, J.- 
[111] A.E. Takesian, T.K. Hensch, Balancing Plasticity/Stability Across Brain Development, 1st ed., Elsevier B.V, 2013. doi:10.1016/B978-0-44463327-9.00001-1.

[112] F.M. Vaccarino, E.L. Grigorenko, K.M. Smith, H.E. Stevens, Regulation of Cerebral Cortical Size and Neuron Number by Fibroblast Growth Factors: Implications for Autism, J Autism Dev Disord. 39 (2008) 511520. doi:10.1007/s10803-008-0653-8.

[113] I.H.M. Smart, C. Dehay, P. Giroud, M. Berland, H. Kennedy, Unique morphological features of the proliferative zones and postmitotic compartments of the neural epithelium giving rise to striate and extrastriate cortex in the monkey, Cereb. Cortex. 12 (2002) 37-53.

[114] N. Zecevic, Y. Chen, R. Filipovic, Contributions of cortical subventricular zone to the development of the human cerebral cortex, J. Comp. Neurol. 491 (2005) 109-122. doi:10.1002/cne.20714.

[115] N. Bayatti, J.A. Moss, L. Sun, P. Ambrose, J.F.H. Ward, S. Lindsay, et al., A molecular neuroanatomical study of the developing human neocortex from 8 to 17 postconceptional weeks revealing the early differentiation of the subplate and subventricular zone, Cerebral Cortex. 18 (2008) 1536-1548. doi:10.1093/cercor/bhm184.

[116] D. Inta, J. Alfonso, J. von Engelhardt, M.M. Kreuzberg, A.H. Meyer, J.A. van Hooft, et al., Neurogenesis and widespread forebrain migration of distinct GABAergic neurons from the postnatal subventricular zone, Proceedings of the National Academy of Sciences. 105 (2008) 2099420999. doi:10.1073/pnas.0807059105.

[117] H. Wichterle, J.M. García-Verdugo, A. Alvarez-Buylla, Direct evidence for homotypic, glia-independent neuronal migration, Neuron. 18 (1997) 779-791.

[118] F. Polleux, K.L. Whitford, P.A. Dijkhuizen, T. Vitalis, A. Ghosh, Control of cortical interneuron migration by neurotrophins and PI3-kinase signaling, Development. 129 (2002) 3147-3160.

[119] N.V. Radonjić, F. Memi, J.A. Ortega, N. Glidden, H. Zhan, N. Zecevic, The Role of Sonic Hedgehog in the Specification of Human Cortical Progenitors In Vitro, Cerebral Cortex. 26 (2015) 131-143. doi:10.1093/cercor/bhu183.

[120] L. Puelles, E. Kuwana, E. Puelles, A. Bulfone, K. Shimamura, J. Keleher, et al., Pallial and subpallial derivatives in the embryonic chick and mouse telencephalon, traced by the expression of the genes Dlx-2, Emx-1, Nkx2.1, Pax-6, and Tbr-1, J. Comp. Neurol. 424 (2000) 409-438.

[121] L. Puelles, Thoughts on the development, structure and evolution of the mammalian and avian telencephalic pallium, Philosophical Transactions of the Royal Society B: Biological Sciences. 356 (2001) 1583-1598. doi:10.1098/rstb.2001.0973.

[122] F. Sugahara, Y. Murakami, N. Adachi, S. Kuratani, Evolution of the regionalization and patterning of the vertebrate telencephalon: what can we learn from cyclostomes? Current Opinion in Genetics \& Development. 23 (2013) 475-483. doi:10.1016/j.gde.2013.02.008.

[123] F. Sugahara, Y. Murakami, J. Pascual-Anaya, S. Kuratani, 
Reconstructing the ancestral vertebrate brain, Development, Growth \& Differentiation. (2017). doi:10.1111/dgd.12347.

[124] I. Cobos, The Avian Telencephalic Subpallium Originates Inhibitory Neurons That Invade Tangentially the Pallium (Dorsal Ventricular Ridge and Cortical Areas), Developmental Biology. 239 (2001) 30-45. doi:10.1006/dbio.2001.0422.

[125] F. Tuorto, P. Alifragis, V. Failla, J.G. Parnavelas, M. Gulisano, Tangential migration of cells from the basal to the dorsal telencephalic regions in the chick, Eur. J. Neurosci. 18 (2003) 3388-3393. doi:10.1111/j.1460-9568.2003.03059.x.

[126] N. Moreno, A. González, S. Rétaux, Evidences for tangential migrations inXenopus telencephalon: Developmental patterns and cell tracking experiments, Devel Neurobio. 68 (2008) 504-520. doi:10.1002/dneu.20603.

[127] C. Metin, C. Alvarez, D. Moudoux, T. Vitalis, C. Pieau, Z. Molnar, Conserved pattern of tangential neuronal migration during forebrain development, Development. $134 \quad$ (2007) 2815-2827. doi:10.1242/dev.02869.

[128] Z. Molnár, C. Métin, A. Stoykova, V. Tarabykin, D.J. Price, F. Francis, et al., Comparative aspects of cerebral cortical development, European Journal of Neuroscience. 23 (2006) 921-934. doi:10.1111/j.14609568.2006.04611.x.

[129] N. Moreno, A. González, S. Rétaux, Development and evolution of the subpallium, Seminars in Cell and Developmental Biology. 20 (2009) 735-743. doi:10.1016/j.semcdb.2009.04.007.

[130] D.H. Tanaka, K. Nakajima, Migratory pathways of GABAergic interneurons when they

enter the neocortex, European Journal of Neuroscience. 35 (2012) 1655-1660. doi:10.1111/j.1460-9568.2012.08111.x.

[131] D. Tanaka, Y. Nakaya, Y. Yanagawa, K. Obata, F. Murakami, Multimodal tangential migration of neocortical GABAergic neurons independent of GPI-anchored proteins, Development. 130 (2003) 58035813. doi:10.1242/dev.00825.

[132] D.H. Tanaka, K. Maekawa, Y. Yanagawa, K. Obata, F. Murakami, Multidirectional and multizonal tangential migration of GABAergic interneurons in the developing cerebral cortex, Development. 133 (2006) 2167-2176. doi:10.1242/dev.02382.

[133] B. Nadarajah, J.G. Parnavelas, Modes of neuronal migration in the developing cerebral cortex, Nat Rev Neurosci. 3 (2002) 423-432. doi:10.1038/nrn845.

[134] A.R. Kriegstein, S.C. Noctor, Patterns of neuronal migration in the embryonic cortex, Trends in Neurosciences. 27 (2004) 392-399. doi:10.1016/j.tins.2004.05.001.

[135] S. Willi-Monnerat, E. Migliavacca, D. Surdez, M. Delorenzi, R. LuthiCarter, A.V. Terskikh, Comprehensive spatiotemporal transcriptomic analyses of the ganglionic eminences demonstrate the uniqueness of its caudal subdivision, Molecular and Cellular Neuroscience. 37 (2008) 845-856. doi:10.1016/j.mcn.2008.01.009.

[136] M. Salaj, R. Druga, J. Cerman, H. Kubová, F. Barinka, Calretinin and parvalbumin immunoreactive interneurons in the retrosplenial cortex of 
the rat brain_Qualitative and quantitative analyses, Brain Research. 1627 (2015) 201-215. doi:10.1016/j.brainres.2015.09.031.

[137] E. Puzzolo, A. Mallamaci, Cortico-cerebral histogenesis in the opossum Monodelphis domestica: generation of a hexalaminar neocortex in the absence of a basal proliferative compartment, Neural Development. 5 (2010) 8-18. doi:10.1186/1749-8104-5-8.

[138] N. Zecevic, A. Milosevic, Initial development of g-aminobutyric acid immunoreactivity in the human cerebral cortex, J. Comp. Neurol. 380 (1997) 495-506. doi:10.1002/(SICI)10969861(19970421)380:4<495::AID-CNE6>3.0.CO;2-X.

[139] M.F. Paredes, D. James, S. Gil-Perotin, H. Kim, J.A. Cotter, C. Ng, et al., Extensive migration of young neurons into the infant human frontal lobe, Science. 354 (2016) aaf7073-aaf7073. doi:10.1126/science.aaf7073.

[140] I. Carrera, S. Ferreiro-Galve, C. Sueiro, R. Anadón, I. Rodríguez-Moldes, Tangentially migrating GABAergic cells of subpallial origin invade massively the pallium in developing sharks, Brain Research Bulletin. 75 (2008) 405-409. doi:10.1016/j.brainresbull.2007.10.013.

[141] C.G. Van Eden, L. Mrzljak, P. Voorn, H.B. Uylings, Prenatal development of GABA-ergic neurons in the neocortex of the rat, J. Comp. Neurol. 289 (1989) 213-227. doi:10.1002/cne.902890204.

[142] A. Cobas, A. Fairén, G. Alvarez-Bolado, M.P. Sánchez, Prenatal development of the intrinsic neurons of the rat neocortex: a comparative study of the distribution of GABA-immunoreactive cells and the GABAA receptor, Neuroscience. 40 (1991) 375-397.

[143] X.X. Yan, D.S. Zheng, L.J. Garey, Prenatal development of GABAimmunoreactive neurons in the human striate cortex, Developmental Brain Research. 65 (1992) 191-204. doi:10.1016/0165-3806(92)90179-Z.

[144] J.A. Del Río, E. Soriano, I. Ferrer, Development of GABAimmunoreactivity in the neocortex of the mouse, J. Comp. Neurol. 326 (1992) 501-526. doi:10.1002/cne.903260403.

[145] I. DeDiego, A. Smith-Fernández, A. Fairén, Cortical cells that migrate beyond area boundaries: characterization of an early neuronal population in the lower intermediate zone of prenatal rats, Eur. J. Neurosci. 6 (1994) 983-997.

[146] A. Milosevic, S. Kanazir, N. Zecevic, Immunocytochemical localization of growth-associated protein GAP-43 in early human development, Developmental Brain Research. 84 (1995) 282-286. doi:10.1016/01653806(94)00187-5.

[147] G. Meyer, C.G. Perez-Garcia, J.G. Gleeson, Selective expression of doublecortin and LIS1 in developing human cortex suggests unique modes of neuronal movement, Cereb. Cortex. 12 (2002) 1225-1236.

[148] B. Nadarajah, P. Alifragis, R.O.L. Wong, J.G. Parnavelas, Ventricledirected migration in the developing cerebral cortex, Nature Neuroscience. 5 (2002) 218-224. doi:10.1038/nn813.

[149] E.S.B.C. Ang, T.F. Haydar, V. Gluncic, P. Rakic, Four-dimensional migratory coordinates of GABAergic interneurons in the developing mouse cortex, Journal of Neuroscience. 23 (2003) 5805-5815.

[150] G.W. Huntley, S.H.C. Hendry, H.P. Killackey, L.M. Chalupa, E.G. Jones, Temporal sequence of neurotransmitter expression by developing neurons of fetal monkey visual cortex, Developmental Brain Research. 
43 (1988) 69-96. doi:10.1016/0165-3806(88)90154-X.

M.L. Schwartz, D.L. Meinecke, Early Expression of GABA-containing Neurons in the Prefrontal and Visual Cortices of Rhesus Monkeys, Cereb. Cortex. 2 (1992) 16-37. doi:10.1093/cercor/2.1.16.

[152] C. Lois, A. Alvarez-Buylla, Long-distance neuronal migration in the adult mammalian brain, Science. 264 (1994) 1145-1148. doi:10.1126/science.8178174.

[153] C. Wang, F. Liu, Y.-Y. Liu, C.-H. Zhao, Y. You, L. Wang, et al., Identification and characterization of neuroblasts in the subventricular zone and rostral migratory stream of the adult human brain, Nature Cell Biology. 21 (2011) 1534-1550. doi:10.1038/cr.2011.83.

[154] N. Sanai, T. Nguyen, R.A. Ihrie, Z. Mirzadeh, H.-H. Tsai, M. Wong, et al., Corridors of migrating neurons in the human brain and their decline during infancy, Nature. 478 (2011) 382-386. doi:10.1038/nature10487.

[155] O. Marín, J.L.R. Rubenstein, Cell migration in the forebrain, Annu. Rev. Neurosci. $26 \quad$ (2003) 441-483. doi:10.1146/annurev.neuro.26.041002.131058.

[156] C. Metin, R.B. Vallee, P. Rakic, P.G. Bhide, Modes and Mishaps of Neuronal Migration in the Mammalian Brain, Journal of Neuroscience. 28 (2008) 11746-11752. doi:10.1523/JNEUROSCI.3860-08.2008.

[157] K. Bakhshi, S.A. Chance, The neuropathology of schizophrenia: A selective review of past studies and emerging themes in brain structure and cytoarchitecture, Neuroscience. $303 \quad$ (2015) 82-102. doi:10.1016/j.neuroscience.2015.06.028.

[158] K. Nakazawa, V. Zsiros, Z. Jiang, K. Nakao, S. Kolata, S. Zhang, et al., Neuropharmacology, Neuropharmacology. 62 (2012) 1574-1583. doi:10.1016/j.neuropharm.2011.01.022.

[159] T. Uchida, T. Furukawa, S. Iwata, Y. Yanagawa, A. Fukuda, Selective loss of parvalbumin-positive GABAergic interneurons in the cerebral cortex of maternally stressed Gad1-heterozygous mouse offspring, Translational Psychiatry. 4 (2014) e371-10. doi:10.1038/tp.2014.13.

[160] A. Marsman, R.C.W. Mandl, D.W.J. Klomp, M.M. Bohlken, V.O. Boer, A. Andreychenko, et al., GABA and glutamate in schizophrenia: A 7 T 1H-MRS study, Ynicl. 6 (2014) 1-10. doi:10.1016/j.nicl.2014.10.005.

[161] D.A. Lewis, A.A. Curley, J.R. Glausier, D.W. Volk, Cortical parvalbumin interneurons and cognitive dysfunction in schizophrenia, Trends in Neurosciences. 35 (2012) 57-67. doi:10.1016/j.tins.2011.10.004.

[162] R. Batista-Brito, G. Fishell, The developmental integration of cortical interneurons into a functional network, Curr. Top. Dev. Biol. 87 (2009) 81-118. doi:10.1016/S0070-2153(09)01203-4.

[163] S.B. Nelson, V. Valakh, Excitatory/Inhibitory Balance and Circuit Homeostasis in Autism Spectrum Disorders, Neuron. 87 (2015) 684-698. doi:10.1016/j.neuron.2015.07.033.

[164] X. Liu, N. Novosedlik, A. Wang, M.L. Hudson, I.L. Cohen, A.E. Chudley, et al., The DLX1and DLX2 genes and susceptibility to autism spectrum disorders, Eur J Hum Genet. 17 (2008) 228-235. doi:10.1038/ejhg.2008.148.

[165] N. Brew, D. Walker, F.Y. Wong, Cerebral vascular regulation and brain injury in preterm infants, AJP: Regulatory, Integrative and Comparative 
[166] J.J. Volpe, Brain injury in premature infants: a complex amalgam of destructive and developmental disturbances, The Lancet Neurology. 8 (2009) 110-124. doi:10.1016/S1474-4422(08)70294-1.

[167] B.J. Duff, K.A.N. Macritchie, T.W.J. Moorhead, S.M. Lawrie, D.H.R. Blackwood, Human brain imaging studies of DISC1 in schizophrenia, bipolar disorder and depression: A systematic review, Schizophrenia Research. 147 (2013) 1-13. doi:10.1016/j.schres.2013.03.015.

[168] G. Bartolini, G. Ciceri, O. Marín, Integration of GABAergic Interneurons into Cortical Cell Assemblies:Lessons from Embryos and Adults, Neuron. 79 (2013) 849-864. doi:10.1016/j.neuron.2013.08.014.

[169] G. Meyer, A.M. Goffinet, Prenatal development of reelinimmunoreactive neurons in the human neocortex, J. Comp. Neurol. 397 (1998) 29-40.

[170] X. Yu, N. Zecevic, Dorsal radial glial cells have the potential to generate cortical interneurons in human but not in mouse brain, Journal of Neuroscience. 31 (2011) 2413-2420. doi:10.1523/JNEUROSCI.524910.2011.

[171] G. Reinchisi, K. Ijichi, N. Glidden, I. Jakovcevski, N. Zecevic, COUPTFII expressing interneurons in human fetal forebrain, Cerebral Cortex. 22 (2012) 2820-2830. doi:10.1093/cercor/bhr359.

[172] A. Fess-Higgins, J.C. Larroche, Le développement du cerveau fœtal humain,Atlas anatomique. Ed. INSERM, Masson Editor. (1987) ISBN: 285598-337.1 


\section{Caption}

Figure 1: Timetable of the development of embryonic cortical structures in human (middle): comparison with mouse (left) and monkey (right).

The panel in the middle shows the development of embryonic cortical structures in the human brain during the first (orange) and second (blue) trimesters of the gestation. Time is counted in gestation weeks (GW, linear scale). During the last (green) trimester of the gestation, cortical layers develop at the expense of subjacent embryonic structures. The embryonic stages defined by Carnegie are indicated on the left side of the timetable. (After [18,20-22,60,61,75,108,114,138,143,169-171])

The panel on the right shows the sequence of development of embryonic cortical structures observed in the monkey brain until mid-gestation. The developmental sequence observed during the 100 first days of the gestation resembles the sequence observed during the first semester of the gestation in human. Time is counted in embryonic days (E, linear scale) (After [109,113])

The panel on the left recalls the sequence of development of embryonic cortical structures in the developing mouse brain. Because of the shortened duration of cortical development in the mouse, the time scale has been expanded. Embryonic structures in the mouse and human cortex derive after the embryonic (E) days 15/16 in mice and the gestation week (GW) 13 in humans

VZ, ventricular zone; SVZ, subventricular zone; iSVZ, inner subventricular zone; IFL, inner fiber layer; oSVZ, outer subventricular zone; OFL, outer fiber layer; ioSVZ, inner oSVZ; ooSVZ, outer oSVZ; IZ, intermediate zone; SP, subplate; CP, cortical plate; MZ, marginal zone; PP, pre plate; PPL, plexiform layer; LI,2,.., layer $1,2, \ldots ;$ sgl, subpial granular layer.

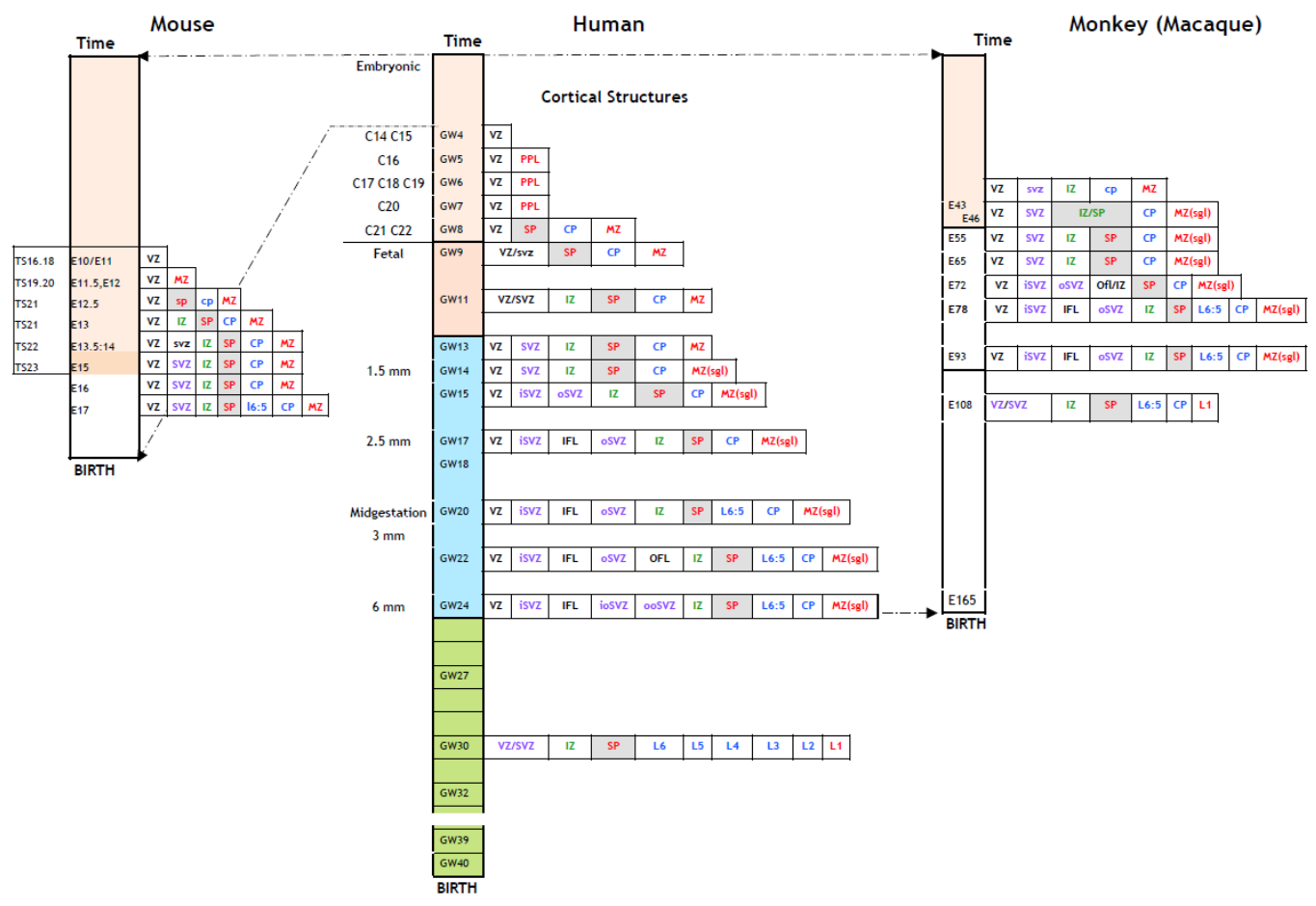


Figure 2: Ontogenic and functional classification of the cortical interneurons (cIN) in the mouse cortex.

A. Distribution of cortical interneurons (cIN) within the 6 layers of the cortex according to their embryonic origin MGE (orange) or CGE (blue) (adapted from [168])

B. Up. Diversity of differentiated cIN. cIN express one of the main three nonoverlapping markers: somatostatin (SST, dark orange), parvalbumin (PV, light orange), and the ionotropic serotonin receptor 5HT3a (5HT3aR, blue). Further subdivisions within each molecular group are revealed by the expression of other markers, as well as morphological, electrophysiological, and synaptic properties not indicated. The different subtypes have different embryonic origins indicated bellow.

Bottom. Mouse subtypes of $\mathrm{cIN}$ are generated from distinct proliferative regions within the subpallium. Boxes indicate the specific and common markers in the ventricular zone (VZ, dark gray) and subventricular zone (SVZ, medium grey) of the medial ganglionic eminence (MGE, orange) and the caudal ganglionic eminence (CGE, blue). Each region produces specific cIN. Markers expressed in the different subpopulations of migrating cIN are indicated in the upper boxes

C. Diagram showing the temporal origin of three subtypes of cIN. Early generated cIN originate from the MGE and give rise to SST+ (pink) or PV+ (orange) cIN. Late generated cIN derive from the CGE and produce VIP+ (blue) (adapted from [162])

D. \& E. Schemes showing the anatomical origin of cINs generated in the MGE and CGE, and their major routes of migration (D. adapted from [34]). E. Trajectories of cIN generated in the MGE (red), CGE (blue) and POA (yellow) on rostral (left) and caudal (right) coronal sections. VZ in dark grey, SVZ in light grey, LGE in green.

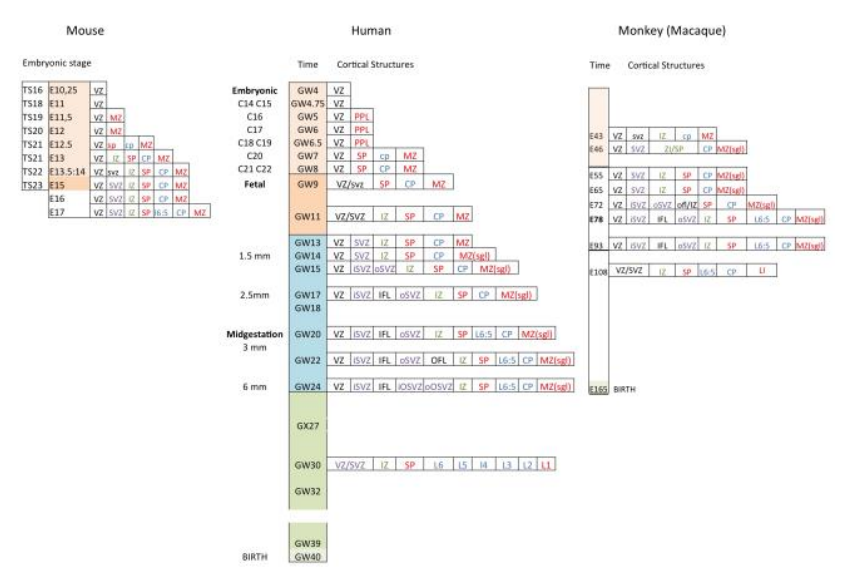




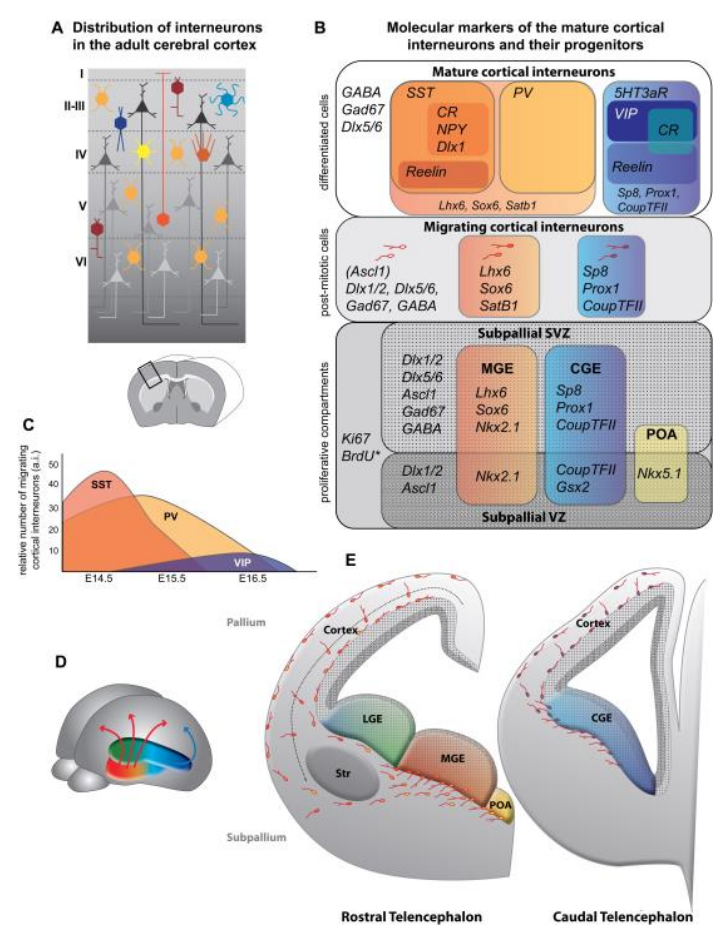


Figure 3: Ontogenic and functional classification of the cortical interneurons (cIN) in the human cortex

A. Boxes illustrate the subpopulations of cortical interneurons cIN in the human cortex identified by their expression of functional and ontogenic markers (modified from [18], abbreviation as in Fig.2). A contingent of calretininexpressing $(\mathrm{CR}+) \mathrm{cIN}$ whose pallial origin is debated is indicated on the right.

B. Boxes summarize the origin of cIN subtypes in human (after $[18,23,75]$ ). cIN are generated from distinct proliferative regions in the medial ganglionic eminence (MGE, orange) and the caudal ganglionic eminence (CGE, blue). The dorsal and ventral parts of the CGE are considered separately. Markers expressed by the putative pallial progenitors of cIN are listed in the grey box (after $[22,60,61,76,108])$. Ventricular zone, VZ, dark gray; subventricular zone, SVZ, medium grey.

C. Schematic representation of frontal sections of the left telencephalic vesicle at gestation weeks (GW) 10,13,17 and 26 in human (after [172]), showing the location and relative size of the lateral ganglionic eminence (LGE, green), MGE (red) and CGE (blue). Rostral level is shown at each stage; caudal level (bottom) is shown only at GW13 and GW17, during the period of maximal CGE expansion. VZ and SVZ in patterned grey.

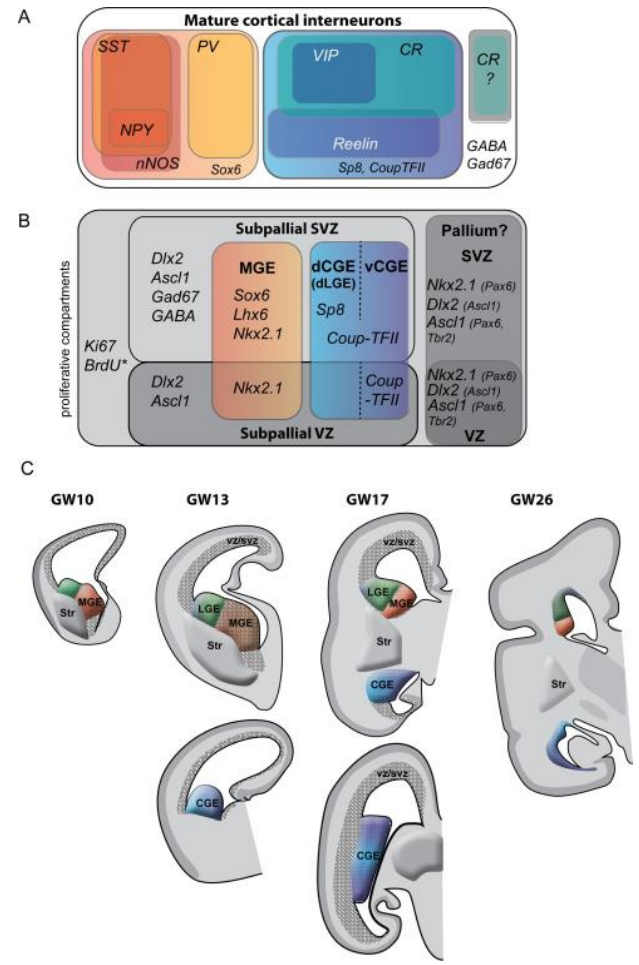


Figure 4: Cortical localization at different gestational ages of cells labeled with interneuron markers (GABA, CR) or transcription factors expressed in subpallial and pallial domains (Ascl1, Dlx2, Nkx2.1, Sox6, Sp8, Coup-TFII)

The figure summarizes results of 8 studies [18,21,22,60,61,114,138,143] that describe the distribution and orientation of GABAergic cIN at different developmental stages in the human cortex.

The distribution of CR+ cells summarizes results published in [21,22,114]. The cortical distribution at same stages of cells expressing transcription factors of the GABAergic lineage is also indicated on the figure (summarizes results published in $[18,22,23,60,61,75,76,108,114,170])$.

For each marker, the color intensity is proportional to the density of labeled cells. The expression of transcription factors in VZ and/or SVZ cortical progenitors, attested by the co-expression of transcription factors and either KI67 or Sox2, is figured by vertical stripes. Arrows indicate the tangential versus radial orientation of cells expressing GABA, CR, or neuronal markers (TUJ1). In transcription factor columns, arrows indicate the alignment of immunostained post-mitotic cells. The figure summarizes data in good agreement with each other, except the column "Nkx2.1" that illustrates results published in $[60,76,108,170]$ in contradiction with results published in $([18,23,75])$, as indicated by the symbol " $€$ ".

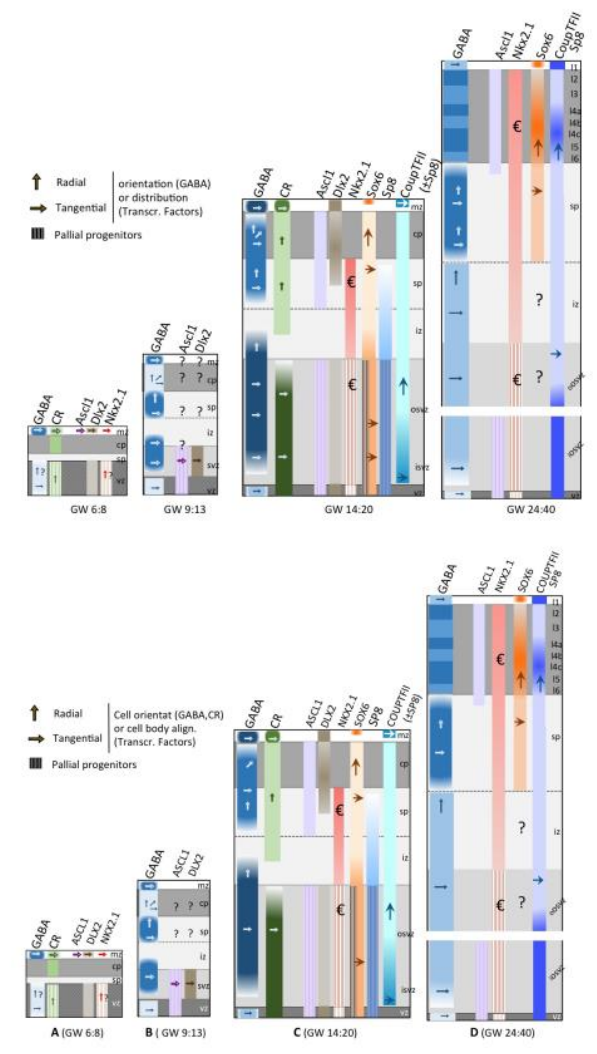

